\title{
Enhanced Gas Recovery by Nitrogen Injection: The effects of injection velocity during natural gas displacement in consolidated rocks
}

\author{
Nuhu Mohammed, Abubakar J. Abbas, Godpower C. Enyi, Donatus E. Edem, Salihu M. Suleiman
}

\begin{abstract}
The choice of the flow velocity in EGR thus becomes important since higher injection rates could lead to premature mixing of the fluids and lower injection rates generally provide longer resident times for the fluids in contact and indirectly increases the mixing of the gases. Additionally, the medium peclet numbers mostly indicate the best injection rates that translate to a smoother displacement with a lower dispersion coefficient during the EGR process. Therefore, $\mathrm{N}_{2}$ Injection into natural gas reservoirs offers the potential to higher recovery efficiency with less mixing compared to conventional $\mathrm{CO}_{2}$ injection. The atmospheric air contained $79 \%$ of $\mathrm{N}_{2}$, making it readily available than $\mathrm{CO}_{2}$ with 400 ppm air composition. More so, $\mathrm{N}_{2}$ requires less compression ratio, which is why a lower amount of it was required to initiate much pressure in the $\mathrm{CH}_{4}$ reservoir during displacement. These made the use of $\mathrm{N}_{2}$ more economically feasible and friendly for the EGR process. A laboratory core flooding experiment was carried out to simulate the effect of injection velocity on $\mathrm{CH}_{4}$ recovery and dispersion coefficient. This was done at $40^{\circ} \mathrm{C}, 1500$ psig, and $0.2-1.0 \mathrm{ml} / \mathrm{min}$ injection rates. The results showed that a medium peclet number could be used to predict the best injection rate that translates to a smoother displacement with a lower dispersion coefficient during the EGR process. $\mathrm{CH}_{4}$ recovery and efficiency were highest at lower injection velocities experienced in both core samples. This could be attributted to insignificance nascent mixing observed as seen on their recorded low longitudinal dispersion coefficient results. Consequence, the experimental runs at high injection rates $(0.6-1.0 \mathrm{ml} / \mathrm{min}) \mathrm{present}$ a different scenario with lower recovery and efficiency due to their high interstitial velocities as the $\mathrm{N}_{2}$ plumes transverses into the core sample during $\mathrm{CH}_{4}$ displacement. Overall, the least methane production and efficiency were noticed in the Bandera core sample as a result of the heterogeneity effect due to the presence of higher clay contents in Bandera than Berea gray. When the capillary forces within the narrower pores in Bandera core sample were overcome, the clay particles occupied those pores thereby sealing some of the flow paths within the pore matrix. This reduces the flow channels, significantly, through which the injected $\mathrm{N}_{2}$ will flow to displace the residual $\mathrm{CH}_{4}$.
\end{abstract}

Keywords: Dispersion coefficient; enhanced gas recovery; breakthrough, concentration profile, methane displacement

\section{Introduction}

Primary oil and gas recovery methods unlock only about $10 \%$ of the oil and gas initially in place, while secondary recovery efforts obtain an additional $20-40 \%$. Therefore, a substantial quantity of oil and gas remains in the formation until more advanced recovery methods are employed. These methods are known as enhanced oil or gas recovery techniques (NiGen report, 2018). Enhanced gas recovery (EGR) and storage by $\mathrm{CO}_{2}$ injection are gaining recognition within the research environment as its combined natural gas $\left(\mathrm{CH}_{4}\right)$ recovery and $\mathrm{CO}_{2}$ storage benefits. Even though, both nitrogen $\left(\mathrm{N}_{2}\right)$ and $\mathrm{CO}_{2}$ can be used to increase hydrocarbons (HCs) yield from oil and gas reservoirs. However, $\mathrm{CO}_{2}$ drawbacks are mainly excessive mixing and high compression ratio, thus hindering the overall process less economical. In contrast, $\mathrm{N}_{2}$ could be easily obtained through cryogenic air separation. It requires less compression ratio than $\mathrm{CO}_{2}$, which is why a lower amount of it was required to initiate much pressure in the $\mathrm{CH}_{4}$ reservoir. Also, the sweetening process cost of natural gas contaminated with $\mathrm{N}_{2}$ is less than that with $\mathrm{CO}_{2}$. This was why the fraction of produced $\mathrm{N}_{2}$ tolerance is higher than the $\mathrm{CO}_{2}$ limit during the natural gas exploration.

The promotion of EGR is still at its infant stage due, to the excessive mixing between the injected (displacing fluid) $\mathrm{CO}_{2}$ and the nascent displaced fluid (natural gas) during the flooding process (Oldenburg \& Benson, 2002; Shtepani, 2006; Turta et al., 2007; Sim et al., 2008; Al-abri et al., 2009; S. Sim et al., 2009; Sidiq et al., 2011; Hughes et al., 2012; Honari et al., 2013; Khan et al., 2013; Zhang et al., 2014; Honari et al., 2015; Patel et al., 2016; Honari et al., 2016). This adulterates the recovered natural gas and thus, reduces its heating and market value, which results in the high cost of the sweetening process to maintain its purity standard for consumption (Oldenburg \& Benson 2002; S. S. K. Sim et al., 2009). Such an overall problem has not only limited the EGR project to a few pilot trials (Pooladi- Darvish et al., 2008) but also made the process apparently uneconomical because of unprecedented mixing with the displaced gas. This makes the whole phenomenon to be poorly understood (Patel et al., 2016). Thus, finding an alternative gas with good displacement properties and minimal miscibility could be a nice development for the oil and gas industry.

Several authors (Xidong et al., 2019; Hughes et al., 2012; Janssen et al., 2018; Abba et al., 2018) have carried out an extensive study on how to delay $\mathrm{CO}_{2}$ breakthrough time during EGR process. Among them, only Abba et al., (2018) and Xidong et al., (2019) were able to achieve reasonable improvement. Abba et al., (2018) use varying connate water concentration and was able to delay $\mathrm{CO}_{2}$ breakthrough by 20 minutes at a concentration of $10 \%$ wt. sodium chloride ( $\mathrm{NaCl}$ ). On the other hand, $\mathrm{Gu}$ et al., (2019) use different mole ratios of $\mathrm{CO}_{2} / \mathrm{N}_{2}$ mixture gases in coalbed core samples. They reveal that injection of $\mathrm{N}_{2}$-rich mixtures contributes to preventing the nascent early breakthrough of injected $\mathrm{CO}_{2}$ and safely stored large volumes of $\mathrm{CO}_{2}$ into the shale sediment over the long term (Xidong et al., 2019). The injection of $\mathrm{CO}_{2}$ into the reservoir generally results in premature breakthrough due to 
nascent mixing with methane, eventually limiting it application for efficient natural gas recovery. This was the reason why many researches on carbon dioxide injections were tailored toward storage rather than recovery. Furthermore, most of the works on the effect of $\mathrm{CO}_{2}$ injection on gas production are simulation-based. Till date, no established efficient alternative gas and injection rate capable of unlocking the residual gas beneath the ground has been highlighted. This necessitated the need for an in-depth study to use $\mathrm{N}_{2}$ as an alternative to minimize such complex phenomenon of gas-gas miscibility since both $\mathrm{CO}_{2}$ and $\mathrm{CH}_{4}$ are miscible in all outcomes (Abba et al., 2018; Honari et al., 2016; Liu et al., 2018). The choice of the flow velocity in EGR thus becomes important since higher injection rates could lead to premature mixing of the fluids while lower injection rates generally provide longer resident times for the fluids in contact and indirectly increases the mixing of the gases yet again. In this research, the experimental study of the effect of $\mathrm{N}_{2}$ injection rates during the EGR process using consolidated rocks was conducted. Determining the best and optimum injection rate is vital for better recovery and less miscibility. This could provide reservoir engineers, geologist, and production engineers with the desired tools to successfully characterize the transport of injected $\mathrm{N}_{2}$ as it plumes transverse within the porous media during the displacement process. The mechanism behind the concept of the enhanced gas recovery process is well demonstrated using a dispersion theory as will be explained in the next two sections.

\subsection{Dispersion Theory and Equation}

Newberg and Foh (1988) used a single parameter diffusion-like model based on the 1D Advection-Dispersion equation (Perkins \& Johnston, 1963; Coats et al., 2009). The model is mostly used to describe the flow of gas transport through a porous medium along the x-direction as shown in Eq. 2.1:

$$
\mathrm{K}_{\mathrm{L}} \frac{\partial^{2} \mathrm{C}}{\partial \mathrm{x}^{2}}-\mathrm{u} \frac{\partial \mathrm{C}}{\partial \mathrm{x}}=\frac{\partial \mathrm{C}}{\partial \mathrm{t}}
$$

The effluent composition $(C)$ from the $G C$ at distance $(x)$ under time $(t)$, longitudinal dispersion coefficient $\left(K_{L}\right)$, and interstitial velocity $(\mathrm{u})$ are key parameters in the above equation. The displacement of methane by $\mathrm{N}_{2}$ in consolidated rocks is governed by Eq. 2.1. This model is widely accepted to simulate fluids movement in porous medium. However, simulation studies have proved that using the equation in its current form resulted in some abnormal behaviour named upstream migration. It occurs especially when the concentration gradient $(\mathrm{dC} / \mathrm{dx})$ along the length scale becomes positive, which is invariable like the case of supercritical $\mathrm{N}_{2}$ flowing through a contaminant after breakthrough in the porous medium generating a large magnitude of both $\mathrm{dC} / \mathrm{dx}$ and dispersion coefficient. Invariably Eq. 2.1 can be re-written in a dimensionless form (Mamora and Seo, 2002) as follows;

$$
\frac{1}{P_{e}} \frac{\partial^{2} C}{\partial x_{D}^{2}}-\frac{\partial C}{\partial x_{D}}=\frac{\partial C}{\partial t_{D}}
$$

Where;

\begin{tabular}{lcc}
\hline \multicolumn{1}{c}{ Parameter } & Symbol & Expression \\
\hline Peclet number & $P_{e}$ & $\frac{u L}{K_{L}}$ \\
Dimensionless time & $t_{D}$ & $\frac{t u}{L}$ \\
Dimensionless distance & $x_{D}$ & $\frac{x}{L}$ \\
Interstitial velocity & $u$ & $\frac{\mathrm{Q}}{\pi r^{2} \phi}$ \\
& & $\pi$ \\
\hline
\end{tabular}

Since the injection of $N_{2}$ is at $x=0$, then

Initial condition: $\mathrm{C}=0$ at $\mathrm{t}_{\mathrm{D}}=0$,

Boundary conditions: $\mathrm{C}=1$ at $\mathrm{x}_{\mathrm{D}}=0, \mathrm{C} \rightarrow 0$ as $\mathrm{x}_{\mathrm{D}} \rightarrow \infty$

Therefore, the solution to Eq. 2.2 maybe presented as follows:

$$
C=\frac{1}{2}\left\{\operatorname{erfc}\left(\frac{x_{D}-t_{D}}{2 \sqrt{t_{D} / P_{e}}}\right)+e^{P_{e} x_{D}} \operatorname{erfc}\left(\frac{x_{D}+t_{D}}{2 \sqrt{t_{D} / P_{e}}}\right)\right\}
$$

The effluent core flooding composition could be fitted into the analytical solution of the 1D differential Advection Dispersion (AD) equation (Eq.2.3) in terms of the Péclet number to evaluate the corresponding dispersion coefficient. The real dispersion coefficient for the experiment is the value which provides the optimum synergy between the experimental result compared to the numerical solution.

In (1963) Perkins \& Johnston proposed a widely accepted model that can predict the dominant displacement mechanism during the EGR process in a porous medium. This model equation can be present as: 


$$
\mathrm{P}_{\mathrm{em}}=\frac{u_{m} d}{D}
$$

Where;

$P_{\text {exp }}$ is the experimental medium Péclet number, which can be evaluated using the average interstitial velocity (u) in $\mathrm{m} / \mathrm{s}, D$ is the molecular diffusion coefficient in $\mathrm{m}^{2} / \mathrm{s}$, and $d$ is the characteristic length scale in meters. The characteristic length scale is defined as the average medium-grain diameter of the core sample or sand pack. Generally, at $P_{\mathrm{em}}<0.1$, diffusion dominates the dispersion process, and at $P_{\text {em }}>10$ advective mixing dominates the dispersion process. The analytical solution to Eq.2.3 is used to fit the concentration profiles obtained from the experimental data to evaluate the dispersion coefficient.

Coats et al., (2009) correlated the dispersion coefficient with the molecular diffusion coefficient as shown in Eq. 2.5 .

$$
\frac{K_{l}}{D}=\frac{1}{\tau}+\alpha \frac{u_{m}^{n}}{D}
$$

Here, $\alpha$ is in meter $(\mathrm{m})$ and is called the dispersivity of the porous medium, and $\mathrm{n}$ represent an exponent. The tortuosity $(\tau)$ can range from 1 to as high as 13 or more for consolidated rocks.as reported by Honari et al., (2013). The tortuosity $\tau$, can be obtained empirically through various methods, whereas $\mathrm{n}$ is mostly determined using a core flooding system (Hughes et al., 2012).

\subsection{Diffusion theory and equation}

The diffusion coefficient (D) signifies the extent or magnitude at which a substance or fluid disperses through a unit area $\left(\mathrm{m}^{2}\right)$ per unit time $(\mathrm{s})$ at a given unit of a concentration gradient. The proposed empirical model which relates the molecular diffusion, temperature, and pressure for empirical diffusion coefficient determination as indicated by (Hughes et al., 2012; Liu et al., 2015) was developed by Takahashi and Iwasaki in (1970). Similarly, empirical equation has been tested by various researches in determining the real and accurate diffusivity using Eq.2.6 at conditions applicable to EGR by $\mathrm{CO}_{2}$ injection. The diffusion coefficient of $\mathrm{CO}_{2}$ in $\mathrm{CH}_{4}$ was dignified at 298-348K and pressures of 5-15MPa in a porous bronze plug (Takahashi and Iwasaki, 1970). The results were well within the range of conditions applicable to the EGR process (Abba et al., 2017).

$$
D_{\mathrm{CO} 2, \mathrm{CH} 4}=\frac{\left(-4.3844 \times 10^{-13} P+8.5440 \times 10^{-11}\right) T^{1.75}}{P}
$$

where $\mathrm{D}_{\mathrm{CO} 2}, \mathrm{CH} 4$ is the molecular diffusion coefficient of $\mathrm{CO}_{2}$ in pure $\mathrm{CH}_{4}$ calculated in $\mathrm{m}^{2} \mathrm{~s}^{-1}$ with $\mathrm{P}$ in MPa and T in $\mathrm{K}$. The absolute average deviation (AAD) of this correlation from the experimental data was $1.5 \%$ over the range of 298-348K and 5-15 MPa (Abba et al., 2017; Abba et al., 2018). In this study, a different model was used to cater for the inclusion of Nitrogen $\left(\mathrm{N}_{2}\right)$ gas during the natural gas displacement. This model equation was presented in Eq.2.7. it is a correlation formula obtained by Fuller, Schetter, and Gittings (1966) by means of computer-aided correlation of 340 experimental points, expressed as:

$$
D_{\mathrm{N} 2, \mathrm{CH} 4}=\frac{1.0110 \times 10^{-4} T^{1.75} \sqrt{\left(1 / \mu_{N_{2}}+1 / \mu_{C H_{4}}\right)}}{P\left[\left(\sum V_{N_{2}}\right)^{1 / 3}+\left(\sum V_{C H_{4}}\right)^{1 / 3}\right]^{2}}
$$

Where $\left(\sum V_{N_{2}}\right)$ and $\left(\sum V_{C_{4}}\right)$ are the values derived from the summation of atomic diffusion volumes of $\mathrm{N}_{2}$ and $\mathrm{CH}_{4}$ molecules respectively. These values and other simple molecules are presented in Table 1. 
Table 1

Atomic diffusion contributions for various gas element and molecules

\begin{tabular}{lcc}
\hline $\mathrm{S} / \mathrm{N}$ & Molecule & Diffusion volume \\
\hline 1 & $\mathrm{He}$ & 2.67 \\
2 & $\mathrm{Ne}$ & 5.98 \\
3 & $\mathrm{Ar}$ & 16.2 \\
4 & $\mathrm{Kr}$ & 24.5 \\
5 & $\mathrm{Xe}$ & 32.7 \\
6 & $\mathrm{H}_{2}$ & 6.12 \\
7 & $\mathrm{D}_{2}$ & 6.84 \\
8 & $\mathrm{~N}_{2}$ & 18.5 \\
9 & $\mathrm{O}_{2}$ & 16.3 \\
10 & $\mathrm{Air}$ & 19.7 \\
11 & $\mathrm{CO}_{1}$ & 18.0 \\
12 & $\mathrm{CO}_{2}$ & 26.9 \\
13 & $\mathrm{~N}_{2} \mathrm{O}$ & 35.9 \\
14 & $\mathrm{NH}_{3}$ & 20.7 \\
15 & $\mathrm{H}_{2} \mathrm{O}$ & 13.1 \\
16 & $\mathrm{SF}_{6}$ & 71.3 \\
17 & $\mathrm{Cl}_{2}$ & 38.4 \\
18 & $\mathrm{Br}_{2}$ & 69.0 \\
19 & $\mathrm{SO}_{2}$ & 41.8 \\
20 & $\mathrm{C}$ & 15.9 \\
21 & $\mathrm{H}$ & 2.31 \\
22 & $\mathrm{O}$ & 6.11 \\
23 & $\mathrm{~N}$ & 4.54 \\
24 & $\mathrm{~F}$ & 14.7 \\
25 & $\mathrm{Cl}$ & 21.0 \\
26 & $\mathrm{Br}_{2}$ & 21.9 \\
27 & $\mathrm{I}$ & 29.8 \\
28 & $\mathrm{~S}$ & 22.9 \\
\hline $\mathrm{S}$ & &
\end{tabular}

(Source: Fuller et al, 1966)

The equation was further simplified after inserting the values of atomic diffusion volumes and the molecular weight of nitrogen and methane. The same was applied for carbon dioxide and methane displacement mechanism. These simplified equations were presented in equation 2.8 , and 2.9 respectively.

$$
\begin{aligned}
& D_{\mathrm{N} 2, \mathrm{CH} 4}=\frac{10.2 \times 10^{-11} T^{1.75}}{P} \\
& D_{\mathrm{CO} 2, \mathrm{CH} 4}=\frac{8.2 \times 10^{-11} T^{1.75}}{P}
\end{aligned}
$$

where $\mathrm{T}$ and $\mathrm{P}$ are temperatures and pressure in kelvin $(\mathrm{K})$ and megapascal (MPa) respectively. For example, at the same temperature and pressure, Eq.2.9 was validated using the experimental work of Abba et al, (2018). The molecular diffusion coefficient $\left(D_{\mathrm{CO} 2, \mathrm{CH} 4}\right)$ was found to be $22.52 \times 10^{-8} \mathrm{~m}^{2} / \mathrm{s}$, which was $0.18 \%$ absolute average deviation (AAD) when compared with Abba et al, (2018) results.

\section{Materials and method}

In this research, an experimental study using a core flooding system to investigate the effect of injecting velocity during EGR process. The experiment was conducted by saturating the core plug with $\mathrm{CH}_{4}$ and injecting of $\mathrm{N}_{2}$ at different injection rates. The core plugs used were Berea and Bandera Gray sandstones whose properties as presented in Table 2.

\subsection{Materials}

For decades, sandstones core samples have been widely recognised as the best rock for testing the efficiency of chemical surfactants. Berea sandstone is a sedimentary rock whose grains are predominantly sand-sized and are composed of quartz held together by silica. The relatively high porosity and permeability of Berea sandstone make it a good reservoir rock. There are 3 major variations of sandstone namely Slit rock, Liver rock, and Dundee. The one used for this experiment was the Slit rock type with visible laminations and classified as homogenous. It has a permeability rating between $100-300 \mathrm{mD}$. On the other hand, Bandera gray is non-homogenous due to the presence of higher clay contents sealing off the narrower paths within the pore matrix. Thus, making it low permeable and less porous. Both core samples originated from Cleveland quarries in Texas, USA. Core plug of dimension 1.0inch diameter by 3.0-inch length was used as present in Table 2. The mineralogy of the core samples is presented in Table 3. For consistency, the porosity and permeability of the sandstone core samples were determined and compared with the ones provided by the supplier (Kocurek Industries INC, Hard Rock Division, 8535 State Highway 
$36 \mathrm{~S}$ Caldwell, TX 77836, Texas USA). Research-grade $\mathrm{CO}_{2}, \mathrm{~N}_{2}$, and $\mathrm{CH}_{4}$ with a purity greater than $99.99 \%$ were sourced from BOC UK.

Table 2

Dimensions and petrophysical properties of the core plugs

\begin{tabular}{cccccc}
\hline Core sample & $\begin{array}{c}\text { Length } \\
(\mathrm{mm})\end{array}$ & $\begin{array}{c}\text { Diameter } \\
(\mathrm{mm})\end{array}$ & $\begin{array}{c}\text { Bulk Vol. } \\
\left(\mathrm{cm}^{3}\right)\end{array}$ & $\begin{array}{c}\text { Porosity } \\
(\%)\end{array}$ & $\begin{array}{c}\text { Gas Permeability } \\
(\mathrm{md})\end{array}$ \\
\hline Bandera gray & 76.02 & 25.31 & 38.27 & 19.68 & 32 \\
Berea gray & 76.07 & 25.49 & 38.85 & 20.53 & 214 \\
\hline
\end{tabular}

Table 3

The mineral contents of Bandera and Berea gray core samples

\begin{tabular}{|c|c|c|c|c|}
\hline \multirow[t]{2}{*}{ Mineral Class } & \multirow[t]{2}{*}{ Minerals } & \multirow[t]{2}{*}{ Chemical Formula } & \multicolumn{2}{|c|}{ Mineral Rocks (\%) } \\
\hline & & & Berea gray & Bandera gray \\
\hline \multirow[t]{6}{*}{ Phyllosilicates (Clays) } & Muscovite & $\mathrm{KAl}_{2}\left(\mathrm{AlSi}_{3}\right) \mathrm{O}_{10}(\mathrm{OH})_{2}$ & - & - \\
\hline & Biotite & $\mathrm{K}\left(\mathrm{MgFe}^{2+}\right)\left(\mathrm{AISi}_{3}\right) \mathrm{O}_{10}(\mathrm{OH})_{2}$ & - & - \\
\hline & Illite & $\mathrm{K}_{0.75}\left(\mathrm{Al}_{1.75}[\mathrm{MgFe}]_{0.25}\right)\left(\mathrm{Al}_{0.5} \mathrm{Si}_{3.5}\right) \mathrm{O}_{10}(\mathrm{OH})_{2}$ & 1.0 & 10 \\
\hline & Chlorites & $(\mathrm{Mg}, \mathrm{Fe})_{3}(\mathrm{Si}, \mathrm{Al})_{4} \mathrm{O}_{10}(\mathrm{OH})_{\mathrm{s}}(\mathrm{Mg}, \mathrm{Fe})_{3}(\mathrm{OH})_{6}$ & 2.0 & 1.0 \\
\hline & Kaolinites & $\mathrm{Al}_{2} \mathrm{SiO}_{5}(\mathrm{OH})_{4}$ & 5.0 & 3.0 \\
\hline & Montmorillonite & $\mathrm{M}_{0.3} \mathrm{Al}_{2}\left(\mathrm{Al}_{0.3} \mathrm{Si}_{3.7}\right) \mathrm{O}_{10}(\mathrm{OH})_{2} \mathrm{M}^{+}=\mathrm{Ca}^{2+}, \mathrm{Mg}^{2+}, \mathrm{K}^{+}$, etc. & - & - \\
\hline \multirow[t]{2}{*}{ Tectosilicates } & Quartz & $\mathrm{SiO}_{2}$ & 87 & 59 \\
\hline & Albite & $(\mathrm{K}, \mathrm{Na}) \mathrm{AlSi}_{3} \mathrm{O}_{8}$ & 2.0 & 12 \\
\hline \multirow[t]{2}{*}{ Carbonates } & Calcite & $\mathrm{CaCO}_{3}$ & 2.0 & - \\
\hline & Dolomite & $\mathrm{Ca}, \mathrm{Mg}\left(\mathrm{CO}_{3}\right)_{2}$ & 1.0 & 15 \\
\hline Oxides & Ilmenite & $\mathrm{Fe}^{2+} \mathrm{TiO}_{3}$ & - & - \\
\hline
\end{tabular}

\subsection{Apparatus and procedure \\ 3.2.1 Apparatus}

The experimental set-up consists of mainly two units; Core Lab UFS-200 core flooding system with inbuild Smart Flood software and packed column design Agilent 7890A model Gas Chromatography (GC) machine model. The online concentration measurement of core flooding effluents was achieved using the GC machine. These values were used in plotting the injection fluids concentration profile and methane recovery efficiency evaluation as the experiment progress with time. Schematic of the equipment set-up is presented in Fig. 1.

The UFS-200 core flooding system is rated to 5,000 and 3,750 psig overburden and pore pressure respectively. The injection system of the equipment is made up of a pair of dual ISCO two-barrel metering pump system $(A / B$ and $C / D)$ for constant flow, pulseless transition and to maintain an accurate flow rate range of 0 to $200 \mathrm{ml} / \mathrm{min}$ with a maximum pressure rating of 3,750 psig. The pumps are attached to apair of two stainless-steel floating piston accumulators which are also rated for 5,000 psig working pressure and temperature of $177^{\circ} \mathrm{C}$. They are designed for injection of the fluids of interest and can withstand up to 7,500 psig test pressure. Hydraulic pump with a maximum output of 10,000 psig was used to set the overburden confining pressure. The Smart Flood 1.0 software forms an essential unit of the system which interfaces the UFS system and the computer data-acquisition-control (DAC) system hardware. It generates on-screen automatic logging of test data for all measured values like pressures, temperatures, volumes, etc., to a computer data file. A Rosemount Static DP transmitter with an accuracy of $0.0055 \%$ was responsible for measuring the differential pressures across the entire Hassler-type core holder, which was used to house the core sample. The core sample is clutch inside the core holder by a Viton rubber sleeve. A core holder heat jacket (containing $1 \mathrm{~m}$ tubing coil) to simulate the required temperature was also employed with an accuracy of $0.1 \%$. Dome type back pressure regulator integrated into the flooding system ensured the confinement of the desired pressures within the core holder. Such desired pressure was set using $\mathrm{N}_{2}$ cylinder bottle. The effluents from the back-pressure regulator pass through the mass flow controllers, that measure the volume of the actual effluents produced before been analysed by the GC system in place. 


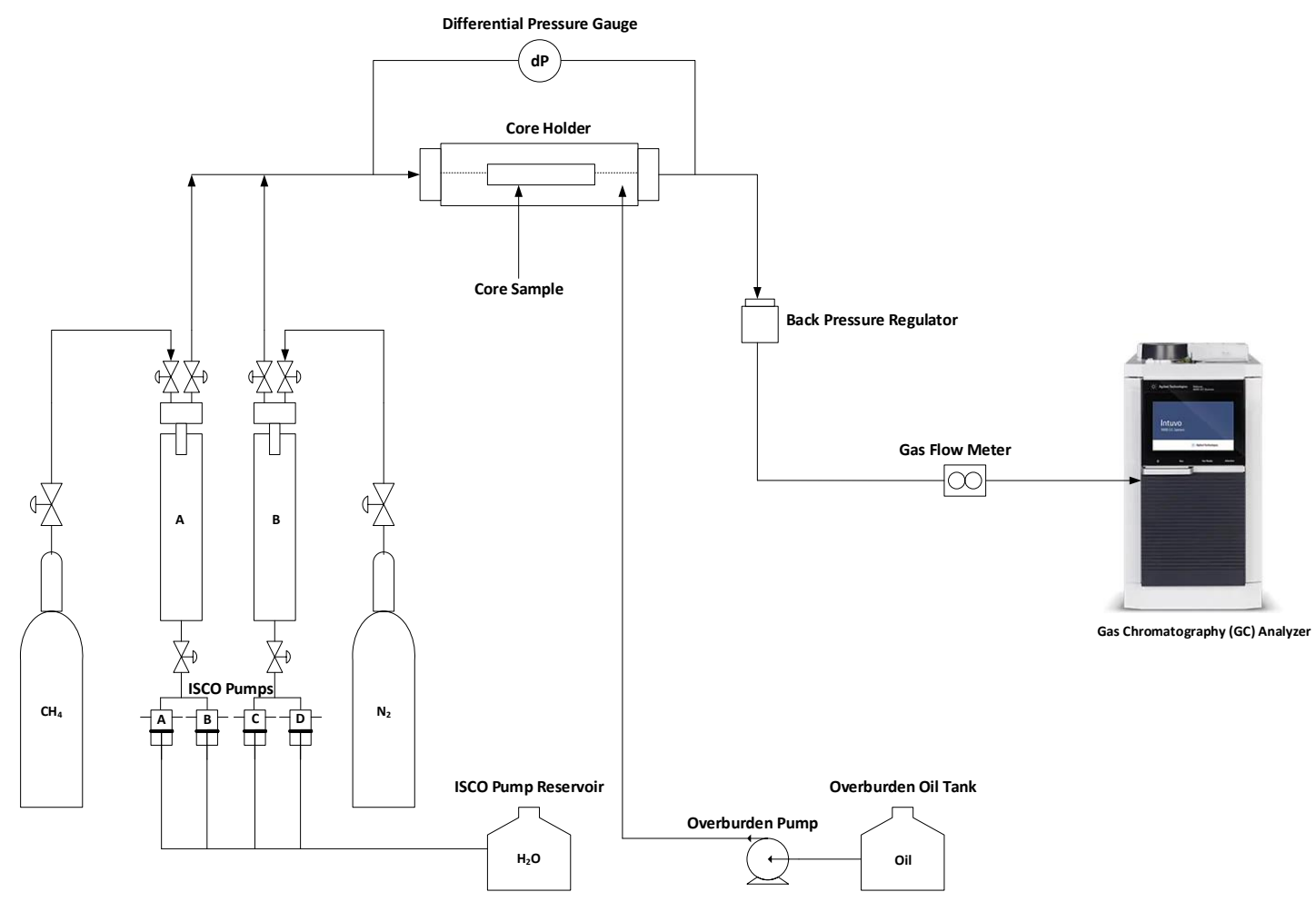

Fig. 1. Schematics of experimentational set-up for $\mathrm{N}_{2}$ gas injection during methane displacement

\subsubsection{Procedure}

The core sample was dried overnight in an oven at $105^{\circ} \mathrm{C}$ for moisture removal and other volatile compounds. The dried sample was wrapped with cling film and then foil paper before inserted into a heat shrink. This is vital to avoid viscous fingering and the penetration of the gases into the ring-shaped core holder through the sleeve. It was then loaded into the core holder and staple with clamps from both ends. Hydraulic oil was then pumped into the ringshaped core holder to provide the desired overburden pressure, which was kept at a minimum of 500 psig above the pore pressures to avoid fracturing of the core sleeve. The heat jacket was then installed on the core holder and the temperature step-up $\left(40^{\circ} \mathrm{C}\right)$ was observed prior to methane saturation. Backpressure was engaged, $\mathrm{CH}_{4}$ was slowly injected into the core sample from the $\mathrm{CH}_{4}$ cylinder through ISCO pumps $\mathrm{A} / \mathrm{B}$ and accumulator or cell $\mathrm{A}$ to saturate the core plug until the GC constantly read methane $>98 \%$. Pumps A/B was stopped and $\mathrm{N}_{2}$ was injected at $0.2 \mathrm{~m} / \mathrm{min}$ using ISCO pumps $\mathrm{C} / \mathrm{D}$ through accumulator or cell $\mathrm{B}$. The experiment elapsed when the methane concentration was insignificant from the $\mathrm{GC}$ reading or the $\mathrm{CO}_{2}$ concentration was $>98 \%$. Further runs were carried out at increasing $\mathrm{N}_{2}$ injection rates of $0.4,0.6,0.8$, and $1.0 \mathrm{~m} / \mathrm{min}$. These flowrates were selected based on the medium peclet number $\left(\mathrm{P}_{\mathrm{em}}\right)$ presented in Table 4. At each injection time of the GC, the time was noted and the effluent composition which was later used to evaluate $\mathrm{CH}_{4}$ recovery efficiency and dispersion coefficient was recorded. The investigation was carried out at 1500 psig pressure and $40^{\circ} \mathrm{C}$ temperature. This condition was chosen based on a normal gas pressure reservoir with a gradient of $0.451 \mathrm{psi} / \mathrm{ft}$, an average reservoir depth of $1 \mathrm{~km}$, and a geothermal temperature of 35$40^{\circ} \mathrm{C} / \mathrm{km}$.

\section{Results and Discussion}

\subsection{Original Gas in Place (OGIP) Determination}

In order to evaluate the $\mathrm{CH}_{4}$ recovery efficiency of each injection rate, the Original Gas in Place (OGIP) must be determined.

$$
\text { OGIP }=\frac{\mathrm{V}_{\mathrm{b}} \phi\left(1-\mathrm{s}_{\mathrm{w}}\right)}{\mathrm{Bg}_{\mathrm{g}}}
$$

$V_{b}$ is the bulk volume of the reservoir $f^{3}, \phi$ is reservoir porosity, $S_{w}$ is formation water saturation, and $B g$ is gas formation volume factor, $f^{3} / s c f$.

$$
\mathrm{B}_{\mathrm{g}}=\frac{\mathrm{P}_{\mathrm{sc}}}{\mathrm{T}_{\mathrm{sc}}} \times \mathrm{z} \frac{\mathrm{T}}{\mathrm{P}}
$$

Where $\mathrm{z}$ is gas compressibility factor, $\mathrm{P}_{s c}$ and $T_{s c}$ are pressure and temperature at standard conditions; $\mathrm{P}$ and $\mathrm{T}$ are pressure and temperatures at desired conditions. Taking $P_{s c}$ and $T_{s c}$ to be $14.696 \mathrm{psia}$ and $18^{\circ} \mathrm{C}(291.15 \mathrm{~K})$, Eq. 2.11 becomes; 


$$
\mathrm{B}_{\mathrm{g}}=\mathrm{z} \frac{\mathrm{T}}{20 \mathrm{P}}
$$

To determine the $\mathrm{z}$ factor from chart, a pseudo-reduced properties/conditions of $\mathrm{CH}_{4}$ at the experimental conditions must be deduced. The correlation for the pseudo pressure is presented as follows:

$$
\mathrm{P}_{\mathrm{r}}=\frac{\mathrm{P}}{\mathrm{P}_{\mathrm{c}}}
$$

And for the temperature;

$$
\mathrm{T}_{\mathrm{r}}=\frac{\mathrm{T}}{\mathrm{T}_{\mathrm{c}}}
$$

Where $P_{r}$ is pseudoreduced pressure, $P$ and $T$ are the experimental pressure (1500 psig) and temperature (313.15 $\mathrm{K}$ ), respectively, $P_{c}$ is the critical pressure (46 bar or $676 \mathrm{psig}$ ), $T_{r}$ is the pseudoreduced temperature, $T_{c}$ is the critical temperature of the gas in $\mathrm{K}$. These parameters input variables to evaluate the $\mathrm{z}$ factor using the Standing and Katz (1941) chart.

$$
\begin{aligned}
& \mathrm{P}_{\mathrm{r}}=\frac{1500}{676}=2.22 \\
& \mathrm{~T}_{\mathrm{r}}=\frac{313.15}{190.6}=1.64
\end{aligned}
$$

Using these values, gas compressibility factor, z, was obtained from the Standing and Katz chart as 0.86 .

The obtained $\mathrm{z}$ factor was then inputted in Eq. 2.12 and $B_{g}$ was computed as:

$$
\mathrm{B}_{\mathrm{g}}=0.87 \times \frac{313.15}{20 \times 1500}=0.00867 \mathrm{~cm}^{3} / \mathrm{scm}^{3}
$$

The porosities and bulk volumes from Table 2 were used to calculate the OGIP of the core plugs. Since the experiment was carried out under dried condition, $\mathrm{S}_{\mathrm{w}}=0$

$$
\text { OGIP }=\frac{38.27 \times 0.1968(1-0)}{0.00867}=868.7 \mathrm{~cm}^{3}
$$

These results summarily is presented in Table 4.

\section{Table 4}

Petrophysical properties and OGIP for the core plugs under investigation

\begin{tabular}{ccccccc}
\hline Core sample & $\begin{array}{c}\text { Length } \\
(\mathbf{m m})\end{array}$ & $\begin{array}{c}\text { Diameter } \\
(\mathbf{m m})\end{array}$ & $\begin{array}{c}\text { Porosity } \\
(\%)\end{array}$ & $\begin{array}{c}\text { Bulk Volume } \\
\left(\mathbf{c m}^{3}\right)\end{array}$ & $\begin{array}{c}\text { Gas in Place } \\
\left(\mathbf{c m}^{3}\right)\end{array}$ & $\begin{array}{c}\text { Gas in Place } \\
(\mathbf{P V})\end{array}$ \\
\hline Bandera gray & 76.02 & 25.31 & 19.68 & 38.27 & 868.7 & 115 \\
Berea gray & 76.07 & 25.23 & 20.53 & 38.85 & 919.94 & 115 \\
\hline
\end{tabular}

PV means pore volume

The OGIP mainly depends on the rock porosity and bulk volume as evidence with the Berea gray core sample recording approximately $920 \mathrm{~cm}^{3}$ of natural gas within its pore spaces. Thus, the more the number of void spaces within the reservoir rock the larger the quantity of gas required to fill those empty spaces under normal conditions.

\subsection{Repeatability and Reproducibility of the Experimental rig and Method}

The iterability of an experiment is vital as it is an indication that the method employed, and the experimental setup has guarantee reproducibility of result outputs. Prior to the main experiment, test runs were performed to confirm the iterability of the test runs. Two test runs were carried out using $\mathrm{N}_{2}$ as displacing gas at an arbitrary injection rate of $0.6 \mathrm{ml} / \mathrm{min}$, temperature and pressure of $40{ }^{\circ} \mathrm{C}$, and 1500 psig respectively. The concentration profile was generated from the effluent stream concentration recorded by the GC as shown in Fig. 2. The dispersion coefficients were determined for runs 1 and 2 as $7.0 \times 10^{-8}$ and $6.4 \times 10^{-8} \mathrm{~m}^{2} / \mathrm{s}$ respectively. Considering these values, along with Fig. 2 plot, its evidenced that the method and experimental set-up employed have guarantee reproducibility of results. Therefore, the same methodological procedure would be adopted for subsequent experimental runs. 


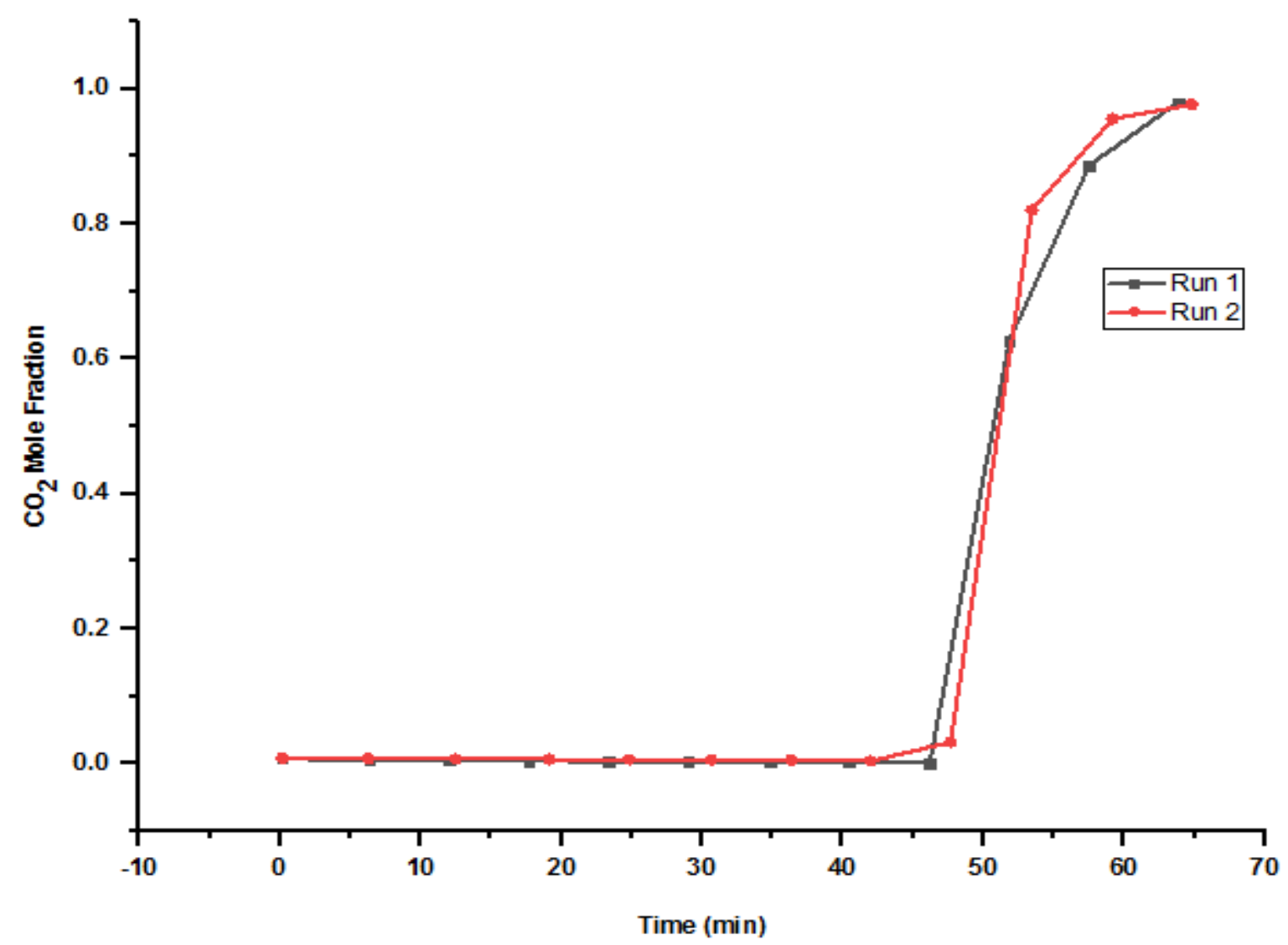

Fig. 2. Concentration profile for repeatability and reproducibility runs at test conditions

The choice of the flow velocity in EGR is important because higher injection rates could lead to premature mixing of the fluids and lower injection rates generally provide longer resident times for the fluids in contact and indirectly increases the mixing of the gases again (Abba et al., 2018). The medium peclet number mostly indicate the best injection rate that translate to a smoother displacement with a lower dispersion coefficient during the EGR process, which gives an overview of the injection scenarios employed in this study. Knowing that the displacement mechanism is dominated by diffusion like pattern, the choice of lower injection rates will provide unwrinkled concentration profiles for proper investigation as averse to higher injection rates. The earlier may likely generate higher mixing, and the later, with high values of medium peclet number, will as well increases the mixing of the fluids resulting in poor sweep efficiency. Thus, selecting moderate or optimum gas injection rate is paramount in order to achieve a sustainable, economical, and efficient EGR process. In this research methane recovery efficiency, dispersion coefficient and other selection criteria were useful in selecting the best or optimum injection rate. For this work the core holder orientation was fixed at horizontal orientation for all the core plugs since the effect of gravity for vertical orientation is insignificant as reported by (Hughes et al., 2012; Liu et al., 2015; Abba et al., 2018).

\subsection{Effect of Injection Rates on Recovery by $\mathrm{N}_{2}$ Injection}

The best $\mathrm{N}_{2}$ injection rate was selected based on high $\mathrm{CH}_{4}$ recovery and low dispersion (mixing). Considering Table 5 , at lower velocities, flow transport in porous media is mostly diffusion like and, on the other hand, it always dispersion dominant at higher flow velocities (Huysmans \& Dassargues, 2005; Yu, Jackson, \& Harmon, 1999). Identifying the displacement phenomenon in fluid transport in porous media is quite important especially when investigating solute transport in sandstone rocks. For numerical and empirical simulation, selecting precise and accurate input variables is a precondition to procuring accurate results, reasonable enough to provide the framework for pilot and field displacement process applicable to the EGR process. Therefore, underrating or overrating the injection rate could lead to wrong prediction which could jeopardise the integrity of the concept aim and render the entire technique uneconomical and inefficient.

From Table 5, all the medium Peclet number value, $P_{e m}$, within the proposed range of injection rate selected $(0.2-$ $1.0 \mathrm{ml} / \mathrm{min}$ ) fall below 0.1 using the grain diameters ( 94.66 and 57.15 micrometre) as length scale of mixing reported by Abba et al., (2018) for Berea and Bandera gay. This implies diffusion is dominant within the range of injection rates for the experiment. However, for Berea gray, the peclet number $\left(P_{\text {exp }}\right)$ evaluated from the assumed dispersion coefficient $\left(\mathrm{K}_{\mathrm{a}}\right)$ at maximum injection $(1.0 \mathrm{ml} / \mathrm{min})$ initially gave an indication of diffusion dominant flow but later showed high values of $P_{\text {exp }}$ at higher injection $(0.8-1.0 \mathrm{ml} / \mathrm{min})$. Thus, making it fell within a transition region between molecular diffusion and mechanical dispersion displacement mechanisms. In both situations where the displacement was dominated by diffusion, the injection rate plays a key role due to its influence on factors that affect mixing between the displacing and displaced fluids. Furthermore, at lower values of $\mathrm{P}_{\exp }$ where diffusion is 
the dominant displacement mechanism, flow is driven by the concentration gradient, and the transport is influence by mobility ratio via the flow velocity (Abba et al., 2019).

Table 5

Peclet number comparison as injection rate selection criteria

\begin{tabular}{|c|c|c|c|c|c|c|}
\hline Core Samples & $\underset{(\mathrm{ml} / \mathrm{min})}{\mathrm{Q}}$ & $\begin{array}{c}\text { Interstitial Velocity } \\
\left(10^{-5} \mathrm{~m} / \mathrm{s}\right)\end{array}$ & $\begin{array}{c}\text { Diffusion Coefficient } \\
\left(10^{-8} \mathrm{~m}^{2} / \mathrm{s}\right)\end{array}$ & $\begin{array}{c}\text { Dispersion Coefficient } \\
\left(10^{-8} \mathrm{~m}^{2} / \mathrm{s}\right)\end{array}$ & $P_{e m}=\frac{u_{m} d_{p}}{D}$ & $P_{\exp }=\frac{u_{m} d}{K_{L m a x}}$ \\
\hline \multicolumn{7}{|l|}{ Berea gray } \\
\hline & 0.2 & 3.18 & 22.99 & 9.12 & 0.013 & 0.033 \\
\hline & 0.4 & 6.36 & 22.99 & 9.12 & 0.026 & 0.066 \\
\hline & 0.6 & 9.54 & 22.99 & 9.12 & 0.039 & 0.099 \\
\hline & 0.8 & 12.72 & 22.99 & 9.12 & 0.052 & 0.132 \\
\hline & 1.0 & 15.90 & 22.99 & 9.12 & 0.066 & 0.165 \\
\hline \multicolumn{7}{|l|}{ Bandera gray } \\
\hline & 0.2 & 3.36 & 22.99 & 13.13 & 0.008 & 0.015 \\
\hline & 0.4 & 6.72 & 22.99 & 13.13 & 0.017 & 0.029 \\
\hline & 0.6 & 10.08 & 22.99 & 13.13 & 0.025 & 0.044 \\
\hline & 0.8 & 13.44 & 22.99 & 13.13 & 0.033 & 0.059 \\
\hline & 1.0 & 16.80 & 22.99 & 13.13 & 0.042 & 0.073 \\
\hline
\end{tabular}

$\mathrm{K}_{\mathrm{Lmax}}$ is the maximum dispersion coefficient for each of the core samples

Tables 11 and 12, in the appendix present the core flooding effluent composition for each of the runs recorded from the gas chromatography for each plug. The Tables presents the percentages by volume of $\mathrm{N}_{2}$ at each injection point at approximately 5 minutes intervals to create a concentration profile in Fig. 3 and 4 . This was used to evaluate the longitudinal dispersion coefficient using Eq. 2.3. The effect of varying injection rates on breakthrough, methane recovery, and dispersion coefficient were presented in Tables 6 and 7, while the plot of methane recovery efficiency against experimental time is shown in Fig. 5 and 6.

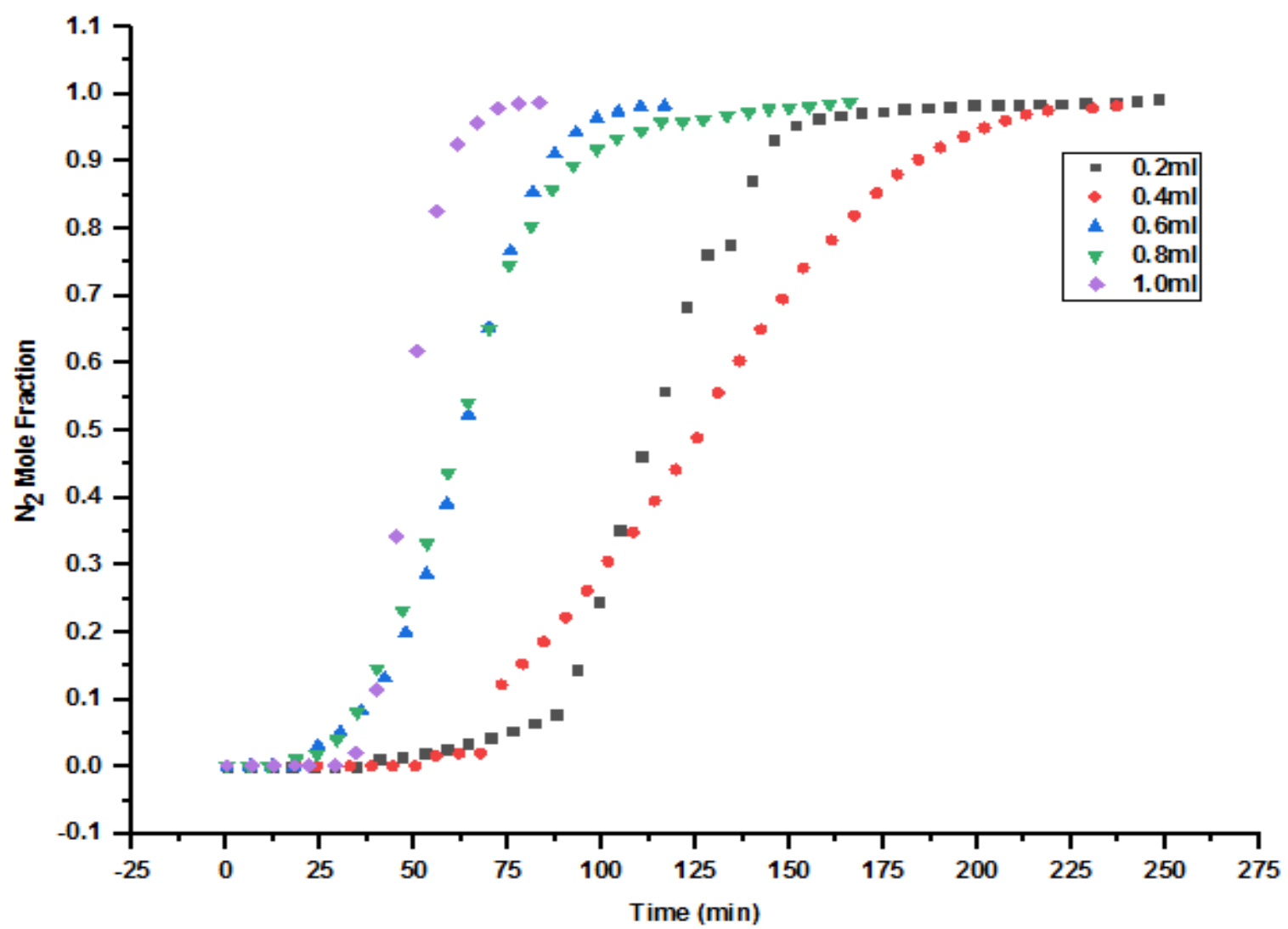

Fig. 3. Concentration profile for Berea gray at varying injection rate $(0.2-1.0 \mathrm{ml} / \mathrm{min})$ 


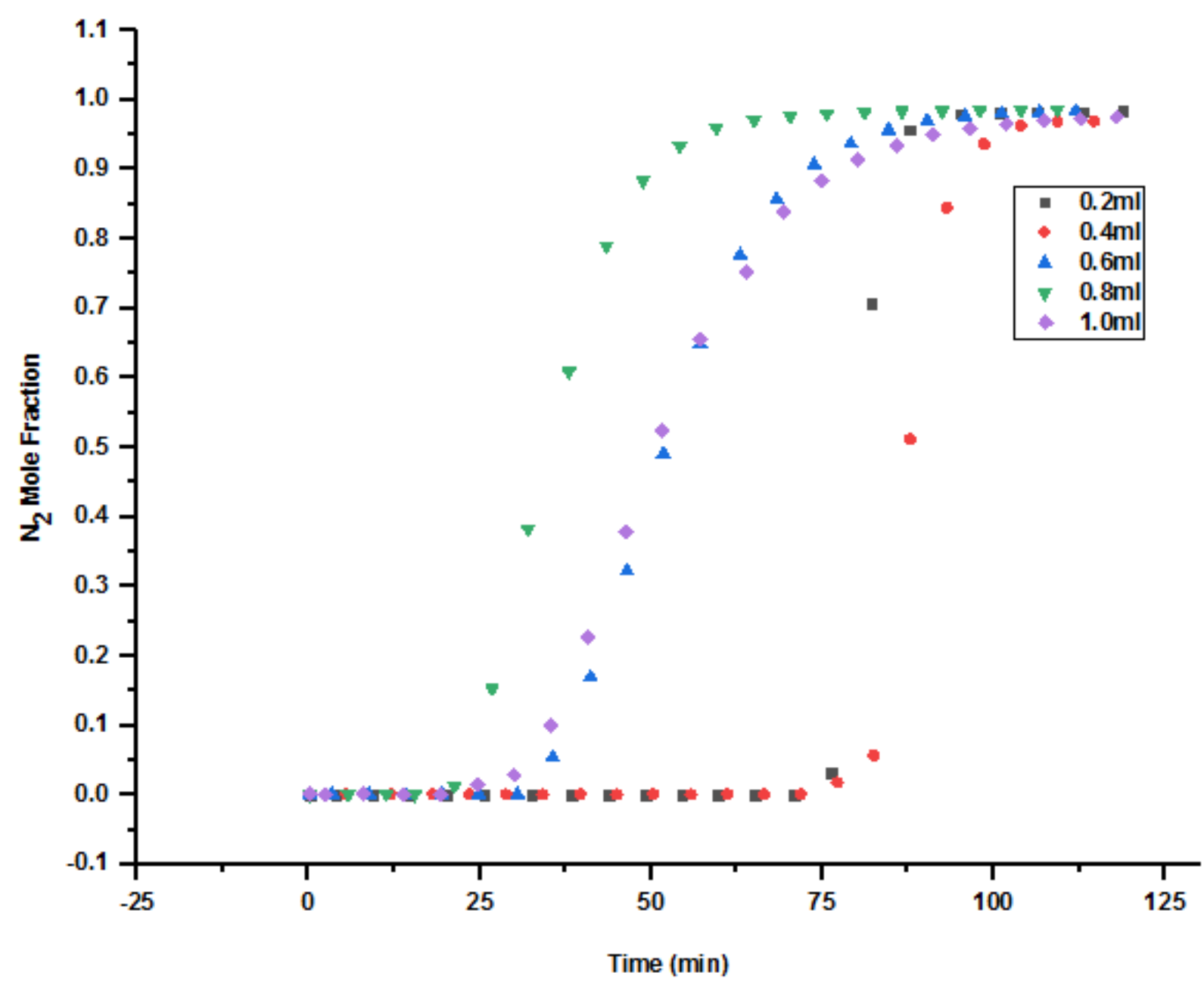

Fig. 4. Concentration profile for Bandera gray at varying injection rate $(0.2-1.0 \mathrm{ml} / \mathrm{min})$

Table 6

Effect of injection rates on $\mathrm{CH}_{4}$ recovery and breakthrough

\begin{tabular}{ccccc}
\hline $\begin{array}{c}\text { Core } \\
\text { Samples }\end{array}$ & $\begin{array}{c}\mathbf{Q} \\
(\mathbf{m l} / \mathbf{m i n})\end{array}$ & $\begin{array}{c}\text { Breakthrough } \\
(\mathbf{m i n})\end{array}$ & $\begin{array}{c}\mathbf{C H}_{\mathbf{4}} \text { Produced } \\
\left(\mathbf{c m}^{\mathbf{3}}\right)\end{array}$ & $\boldsymbol{R F}=\frac{\boldsymbol{C H}_{\mathbf{4}} \text { Preduced }}{\boldsymbol{O G I P}} \times \mathbf{1 0 0}$ \\
\hline Berea gray & & & & \\
& 0.2 & 93.33 & 640.59 & 69.63 \\
& 0.4 & 73.32 & 819.09 & 89.04 \\
& 0.6 & 42.15 & 559.45 & 60.81 \\
Bandera gray & 0.8 & 40.15 & 476.28 & 51.77 \\
& 1.0 & 39.99 & 478.06 & 51.97 \\
& 0.2 & 76.32 & 550.53 & 63.37 \\
& 0.4 & 82.49 & 652.20 & 75.08 \\
& 0.6 & 35.65 & 495.76 & 57.07 \\
& 0.8 & 26.82 & 402.13 & 46.29 \\
& 1.0 & 35.32 & 313.69 & 36.11 \\
\hline
\end{tabular}


Table 7

Dispersion coefficient determination for different $\mathrm{N}_{2}$ injection rates

\begin{tabular}{ccccc}
\hline $\begin{array}{c}\text { Core } \\
\text { Samples }\end{array}$ & $\begin{array}{c}\mathbf{Q} \\
(\mathbf{m l} / \mathbf{m i n})\end{array}$ & $\begin{array}{c}\text { Interstitial Velocity } \\
\left(\mathbf{1 0 ^ { - 5 }} \mathbf{~} \mathbf{m} \mathbf{s}\right)\end{array}$ & $\begin{array}{c}\text { Dispersion Coefficient } \\
\left(\mathbf{1 0}^{-\mathbf{8}} \mathbf{~}^{\mathbf{2}} \mathbf{s}\right)\end{array}$ & $\begin{array}{c}\text { Diffusion Coefficient } \\
\left(\mathbf{1 0 ^ { - 8 }} \mathbf{~}^{\mathbf{2}} \mathbf{s}\right)\end{array}$ \\
\hline Berea gray & & & & \\
& 0.2 & 3.18 & 1.47 & 22.99 \\
& 0.4 & 6.36 & 4.21 & 22.99 \\
& 0.6 & 9.54 & 5.32 & 22.99 \\
Bandera gray & 0.8 & 12.72 & 7.84 & 22.99 \\
& 1.0 & 15.90 & 9.12 & 22.99 \\
& 0.2 & 3.36 & 5.36 & 22.99 \\
& 0.4 & 6.72 & 7.80 & 22.99 \\
& 0.6 & 10.08 & 10.10 & 22.99 \\
& 0.8 & 13.44 & 10.35 & 22.99 \\
& 1.0 & 16.80 & 13.13 & 22.99 \\
\hline
\end{tabular}



Fig. 5. Graphical representation of $\mathrm{CH}_{4}$ volumes produced from all the experiments on Berea gray 


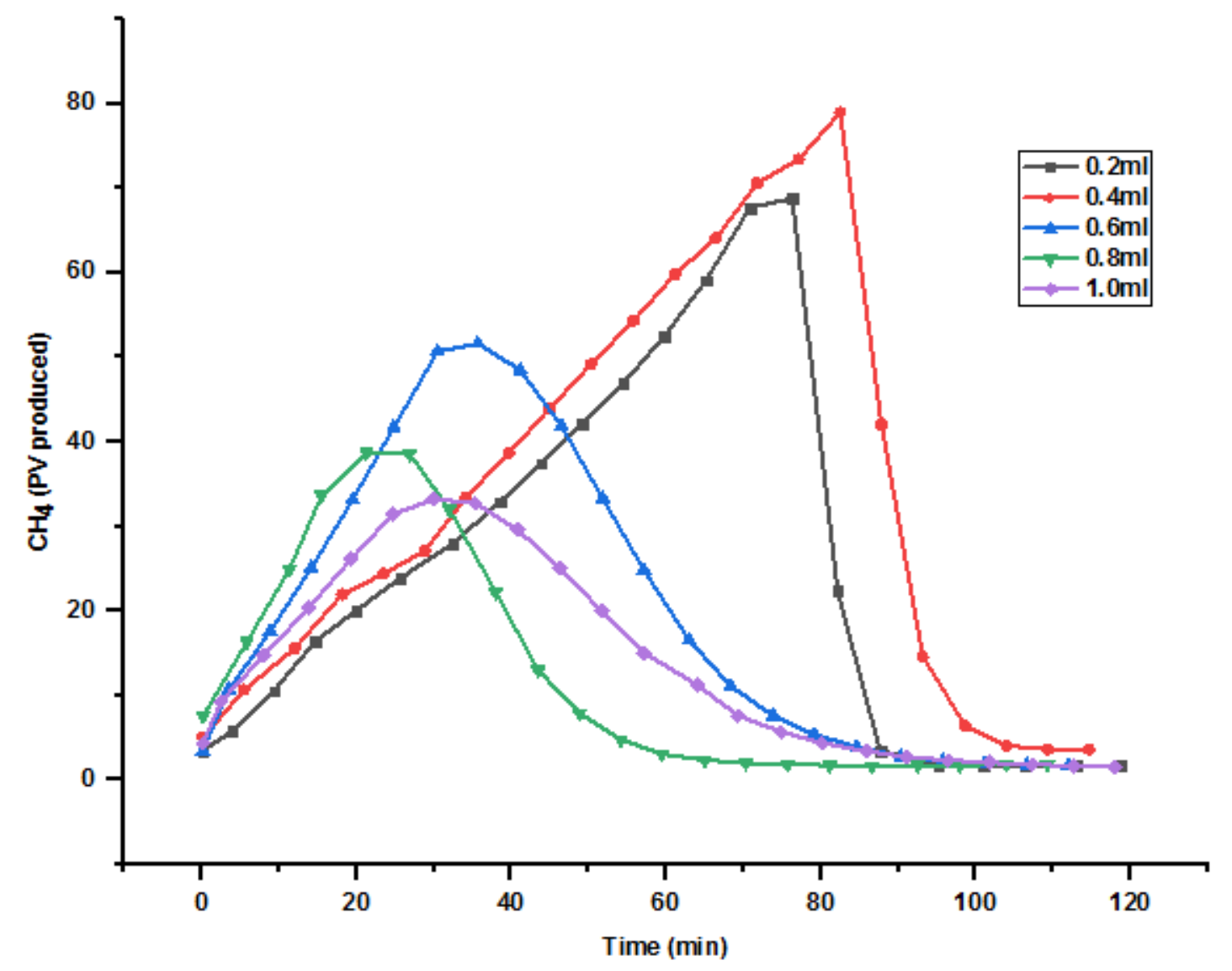

Fig. 6. Graphical representation of $\mathrm{CH}_{4}$ volumes produced from all the experiments on Bandera gray

The selection of the fluid flow velocity during EGR thus becomes important and necessary as higher injection rates usually resulted to premature mixing of the fluids, while lower injection rates mostly lead to a longer resident times (breakthrough) for the fluids in contact during $\mathrm{CH}_{4}$ displacement process. Consequently, it indirectly increases the mixing of these gases. The $P_{\text {exp }}$ values give an indication of the optimum injection rates as presented in Table 5, which then transcribe into a greater displacement and lower or optimum dispersion during the displacement process.

$\mathrm{CH}_{4}$ realised was determined based on the total volume or amount of effluents produced at the end of the core flooding experiment. These volumes were fractions of the original gas in place in the core samples. The results recorded are presented in Tables 8, 13, and 14.

Fig. 5 and 6 are representation of the results of the $\mathrm{CH}_{4}$ recovery efficiency obtained from the core flooding experiments using different injection rates at the same reservoir conditions. These figures are parabolic in shape. The vertical axis represents the cumulative $\mathrm{CH}_{4}$ produced in pore volumes (PV) from time $t=0$ to time $t=t_{x}$, where $x$ is the time at which the $\mathrm{CH}_{4}$ recovery is insignificant as noticed from the online $\mathrm{GC}$ machine. At time $t_{x}$, the experiment comes to an end because most of the $\mathrm{CH}_{4}$ initially in place has been recovered. The set target is to recover $100 \%$ of the $115 \mathrm{PV}$ of the gas initially in place with minimum contamination. Prior to $\mathrm{N}_{2}$ injection, the system was fully saturated with $\mathrm{CH}_{4}$. $\mathrm{N}_{2}$ was then slowly injected at a known rate using the ISCO pump C/D through cell $\mathrm{B}$. As more pore volume of $\mathrm{N}_{2}$ is injected into the system, free contaminate $\mathrm{CH}_{4}$ is produced until breakthrough due to phase change and gravity effect as a result of the rise in pressure. The lower the fraction of $\mathrm{N}_{2}$ produced the more $\mathrm{CH}_{4}$ recovery is recorded. The recovery efficiency is defined as the ratio of $\mathrm{CH}_{4}$ produced to the original gas in place. After the breakthrough, the fraction of $\mathrm{N}_{2}$ in the exit stream begins to rise while $\mathrm{CH}_{4}$ recovery starts declining until it reaches nearly zero at $t=t_{x}$ due to product contamination. The maximum $\mathrm{CH}_{4}$ recovery efficiency was recorded at breakthrough. The breakthrough is set at a $15 \%$ maximum product contamination. In other words, the time at which the mole fraction of $\mathrm{N}_{2}$ produced reached a maximum of 0.15 as shown in Tables 11 and 12 . Considering the experimental run at $0.2 \mathrm{ml} / \mathrm{min}$, the recovery was considerable though the combined breakthrough time was longer and hence a stream of $\mathrm{CH}_{4}$ contaminated by the $\mathrm{N}_{2}$ was recovered as seen in Table 6 . In that, there was a risk of substantial length scale of mixing between $\mathrm{N}_{2}$ and $\mathrm{CH}_{4}$ given the nature of their similarities in property and miscibility despite their low dispersion coefficient values $\left(1.47 \times 10^{-8}\right.$ and $\left.5.36 \times 10^{-8} \mathrm{~m}^{2} / \mathrm{s}\right)$ in Table 7 . Similar trend was observed with $\mathrm{CO}_{2}$ injection at varying injection rates as reported by Abba et al., (2018). This is 
not an economical imitative being the fact that more $\mathrm{CH}_{4}$ will be manufactured which will be highly contaminated by the injected $\mathrm{N}_{2}$ thereby undermining the recovery concept and rendering the EGR process uneconomical.

Consequently, the experimental run at $0.4 \mathrm{ml} / \mathrm{min}$ presents a different scenario with the highest methane recovery and efficiency. There was substantial $\mathrm{CH}_{4}$ recovery and less longitudinal dispersion coefficient in compared to the runs with $0.6-1.0 \mathrm{ml} / \mathrm{min}$ injections that showcases a deficient recovery efficiency, breakthrough time and dispersion coefficient trends due to higher interstitial velocity $\left(9.54-16.80 \times 10^{-5} \mathrm{~m} / \mathrm{s}\right)$ as the $\mathrm{N}_{2}$ plumes transverses through the core sample during the core flooding experiment. More so, high mean interstitial velocities $\left(u_{m}\right)$ grossly increases the molecular kinetic energy, by creating turbulence or eddy current which later influences molecular agitation of the gas, and thus, alleviate the interaction between the displacing and displaced gases. Finally, the summary result shown in Table 8 , provides evidence that the best (optimum) injection rate for $\mathrm{N}_{2}$ injection for both Bandera and Berea gray occurs at $0.4 \mathrm{ml} / \mathrm{min}$ considering its recovery efficiency, longitudinal dispersion coefficient, and breakthrough time values compared to other injection rates $(0.2,0.6,0.8$, and $1.0 \mathrm{ml} / \mathrm{min})$.

Table 8

Effect of injection rates on $\mathrm{CH}_{4}$ recovery and breakthrough

\begin{tabular}{|c|c|c|c|c|c|}
\hline $\begin{array}{c}\text { Core } \\
\text { Samples }\end{array}$ & $\begin{array}{c}Q \mathbf{Q} \\
(\mathrm{ml} / \mathrm{min})\end{array}$ & $\begin{array}{l}\text { Breakthrough } \\
\text { (min) }\end{array}$ & $\begin{array}{c}\mathrm{CH}_{4} \text { Produced } \\
\left(\mathrm{cm}^{3}\right)\end{array}$ & $\mathrm{RF}=\frac{\mathrm{CH}_{4} \text { Produced }}{\text { OGIP }} \times 100$ & $\begin{array}{c}\text { Dispersion Coefficient } \\
\left(10^{-8} \mathrm{~m}^{2} / \mathrm{s}\right)\end{array}$ \\
\hline \multicolumn{6}{|l|}{ Berea gray } \\
\hline & 0.2 & 93.33 & 646.55 & 70.28 & 1.47 \\
\hline & 0.4 & 73.32 & 819.09 & 89.04 & 4.21 \\
\hline & 0.6 & 42.15 & 559.45 & 60.81 & 5.32 \\
\hline & 0.8 & 40.15 & 476.28 & 51.77 & 7.84 \\
\hline & 1.0 & 39.99 & 478.06 & 51.97 & 9.12 \\
\hline \multicolumn{6}{|l|}{ Bandera gray } \\
\hline & 0.2 & 76.32 & 550.53 & 63.37 & 5.36 \\
\hline & 0.4 & 77.16 & 652.20 & 75.08 & 7.80 \\
\hline & 0.6 & 35.65 & 495.76 & 57.07 & 10.10 \\
\hline & 0.8 & 26.82 & 402.13 & 46.29 & 10.35 \\
\hline & 1.0 & 35.32 & 313.69 & 36.11 & 13.13 \\
\hline
\end{tabular}

\subsection{Effect of Injection Rates on Dispersivity}

Looking at Eq. 2.5, It evident that precise and reliable simulation of dispersion in an enhanced recovery process requires a detailed understanding of molecular dispersion (D), tortuosity ( $T$ ), and dispersivity ( $\alpha$ ) at the condition relevant to natural gas displacement in porous media. The latter two parameters are properties of the porous medium (core sample) of which a can be determined from a set of experimental data in which the flow velocity through the medium is increasing at reasonable intervals like those described in this study. Although, the pressure and temperature dependence of longitudinal dispersion coefficient $\left(\mathrm{K}_{\mathrm{L}}\right)$ are acquired predominantly by $\mathrm{D}$, accurate values of the molecular diffusion coefficient are prerequisites to a reliable dispersion correlation. A numerical model developed by Fuller, Schetter, and Gittings (1966) by means of computer-aided correlation of 340 experimental points, expressed in Eq. 2.7 was used to evaluate the molecular diffusion coefficient of $\mathrm{N}_{2}-\mathrm{CH}_{4}$ at conditions relevant to EGR and the miscible displacements. The equation was further simplified by inserting the values of atomic diffusion volumes and the molecular weight of $\mathrm{N}_{2}$ and $\mathrm{CH}_{4}$ as shown in Eq. 2.8. Therefore, using Eq. 2.8, the molecular diffusion coefficients, $D$, at experimental conditions of 1500 psig and $40{ }^{\circ} \mathrm{C}$ of pressure and temperature were evaluated and present in Table 15. Furthermore, the dispersivity $(\alpha)$ can be constructively determined by fixing Eq. 2.5 to the plots of $K_{L} / D$ against $u / D$ which is a straight line as shown in Fig. 7 and 8 . 


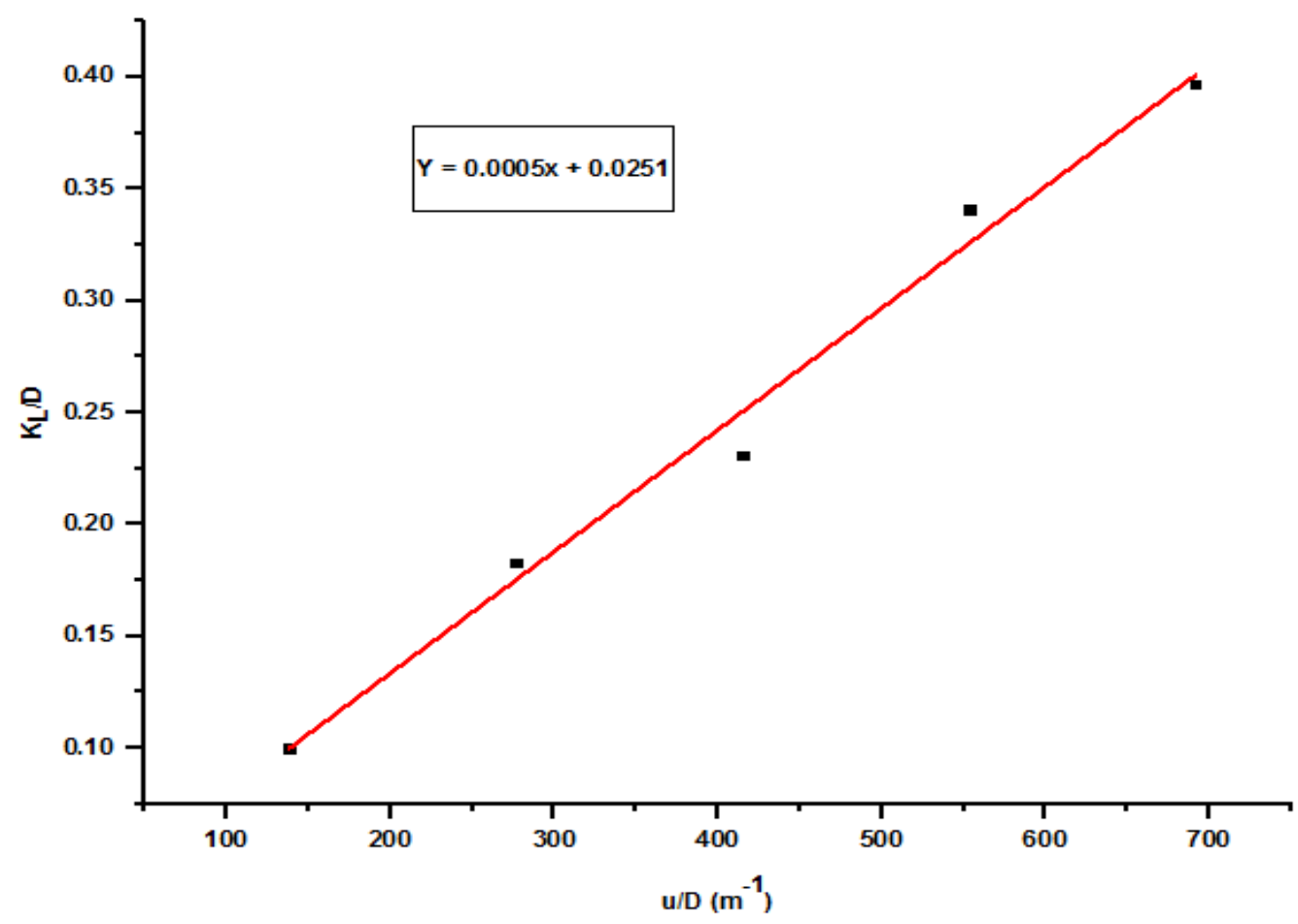

Fig. 7. Plot of dispersion to diffusion coefficient ratio against interstitial velocity for Berea gray

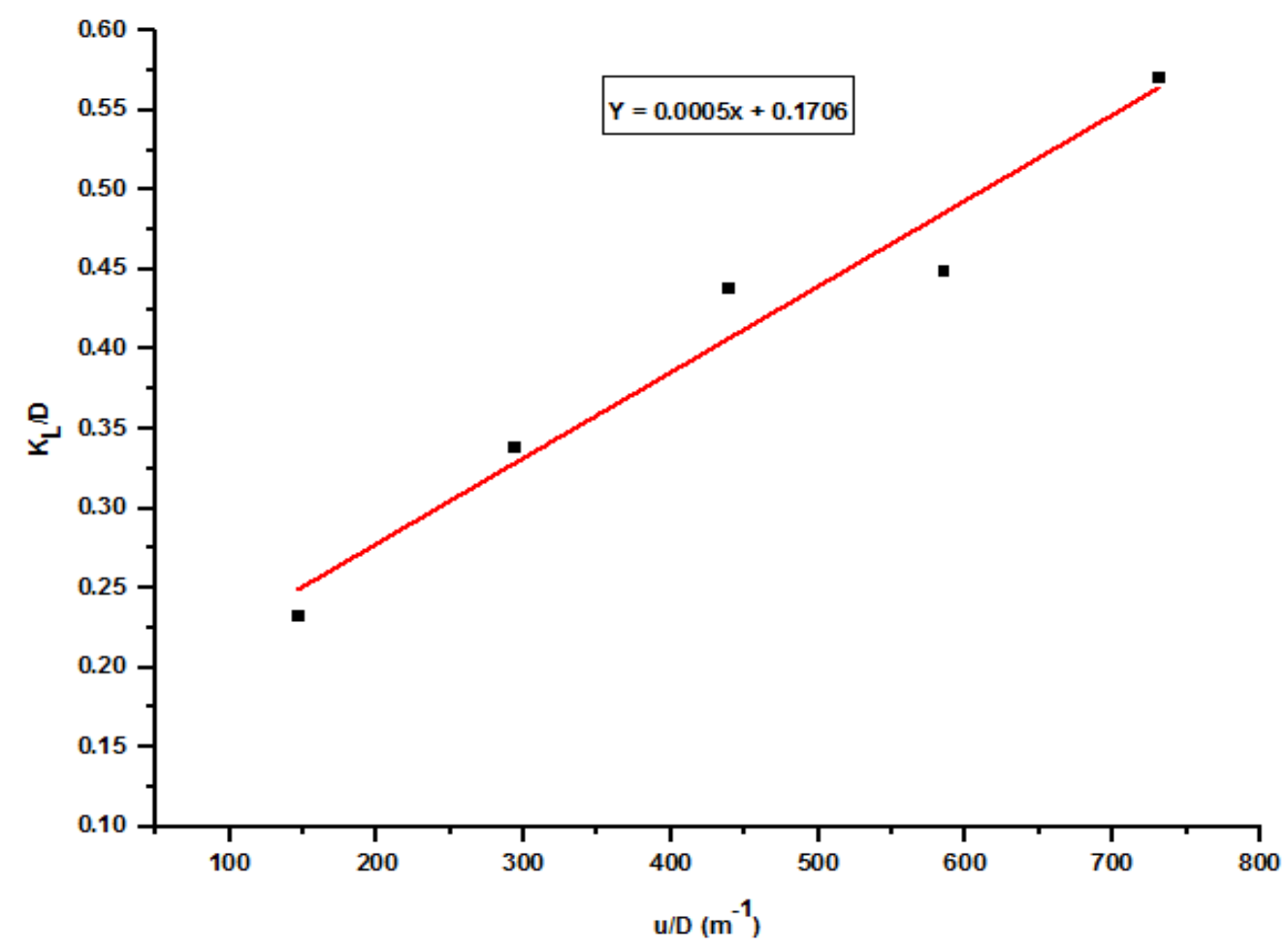

Fig. 8. Plot of dispersion to diffusion coefficient ratio against interstitial velocity for Bandera gray

Also, the effect of injection rates on the longitudinal dispersion coefficient was presented in Fig. 9 and 10 for Berea and Bandera gray respectively. 


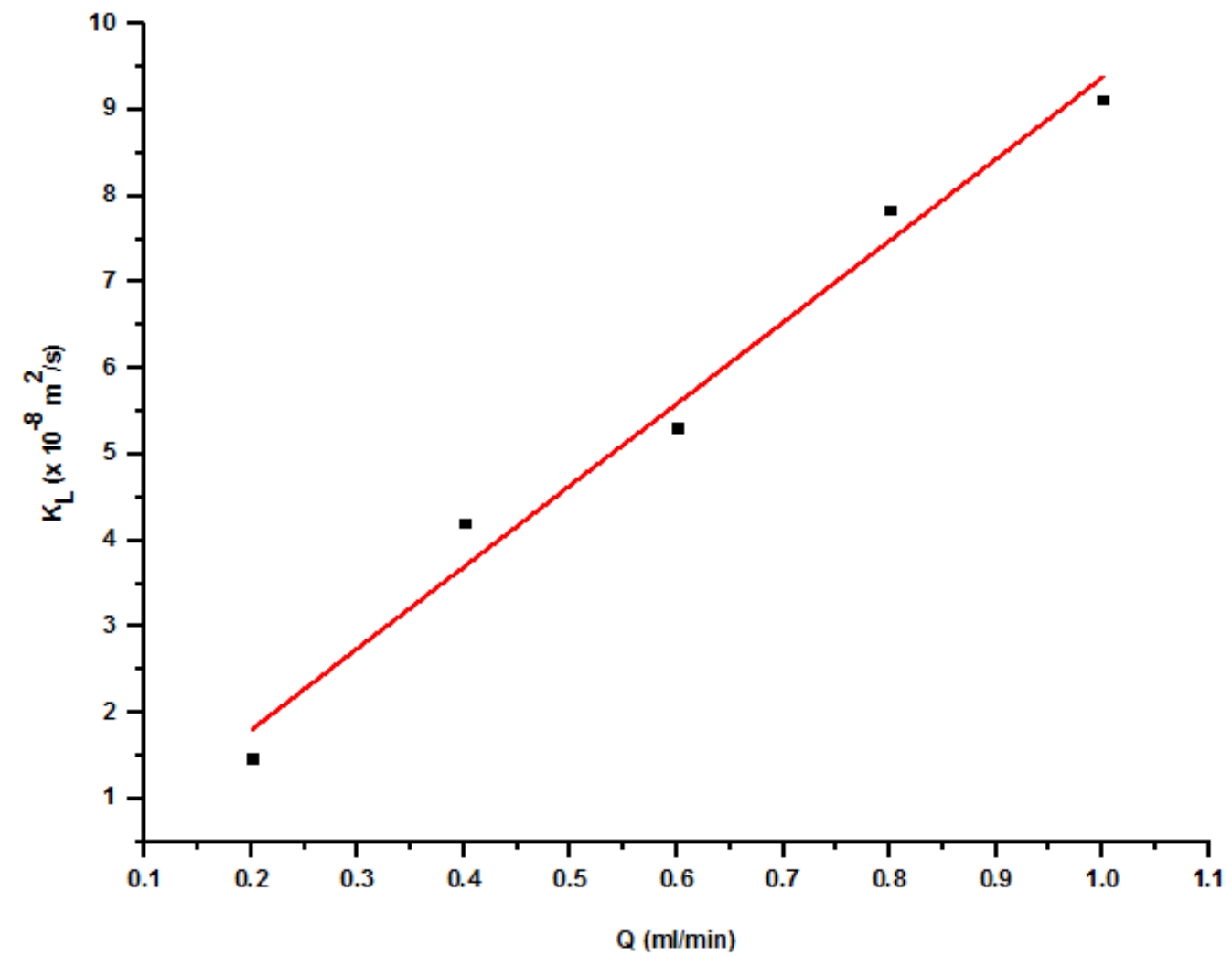

Fig. 9. Relationship of coefficient of longitudinal dispersion with flow injections for Berea gray

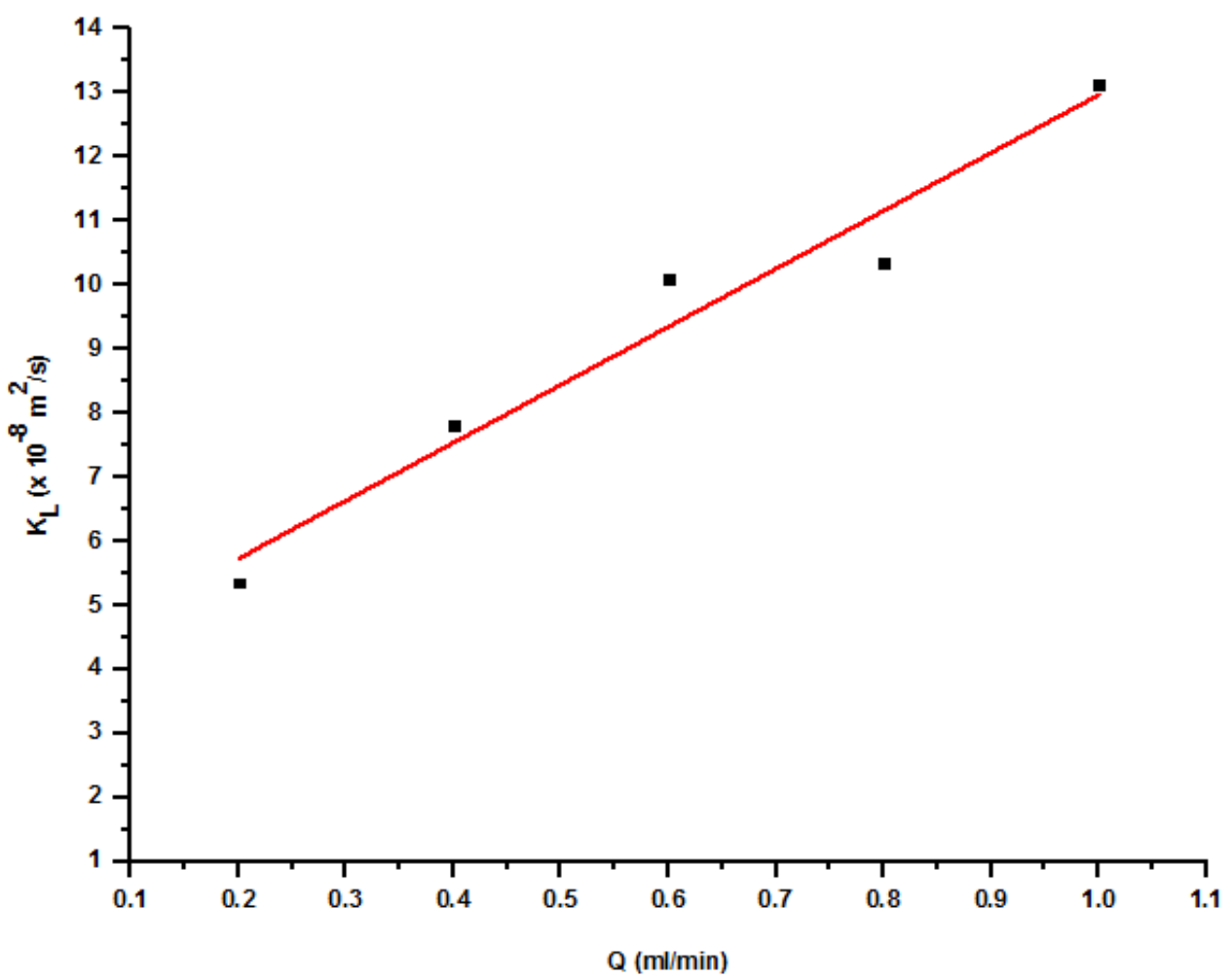

Fig. 10. Relationship of coefficient of longitudinal dispersion with flow injections for Bandera gray 
Reports of (Coats, K.H \& Whitson, 2004; Keith H. Coats et al., 2009; Honari et al., 2013; Hughes et al., 2012; Abba et al., 2018) dispensed that the values of the dispersivity $(\alpha)$ in consolidated porous media are mostly smaller than $0.01 \mathrm{ft}(0.003 \mathrm{~m})$. Hughes et al., (2012) further recorded dispersivity in a range of $0.0001 \mathrm{~m}$ to $0.0011 \mathrm{~m}$ using Donnybrook core sample with petrophysical properties like the ones considered in this work. More so, accurate determination of dispersivity is quite important being an experimental property of a porous medium that examines the characteristic dispersion of the medium by correlating the components of pore velocity to the dispersion coefficient. This parameter is highly sensitive to invigorate fluid flow in the model of the reservoir rock. Considering Fig. 7 and 8 , the dispersivity as measured of the slopes was found to be $0.0005 \mathrm{~m}$ for both Berea and Bandera core samples. This lies within the range of values obtained in the literature. The similarities could be attributed to proximity in their porosities values as indicated in Table 2 . To explain further, the measured dispersivity $(0.0005 \mathrm{~m})$ was employed as the characteristic length scale of mixing in Eq. 2.4 to re-evaluate the medium peclet $\left(P_{e m}\right)$ and experimental peclet $\left(P_{\text {exp }}\right)$ number at varying injection rates. These values were presented in Tables 9.

\section{Table 9}

Peclet numbers determination using a as characteristic length scale of mixing

\begin{tabular}{|c|c|c|c|c|c|c|}
\hline $\begin{array}{c}\text { Core } \\
\text { Samples }\end{array}$ & $\begin{array}{c}Q \\
(\mathrm{ml} / \mathrm{min})\end{array}$ & $\underset{\left(10^{-5} \mathrm{~m} / \mathrm{s}\right)}{u_{m}}$ & $\begin{array}{c}D \\
\left(10^{-8} \mathrm{~m}^{2} / \mathrm{s}\right)\end{array}$ & $\begin{array}{c}\mathrm{KL} \\
\left(10^{-8} \mathrm{~m}^{2} / \mathrm{s}\right)\end{array}$ & $\mathbf{P}_{\mathrm{em}}=\frac{\mathbf{u}_{\mathrm{m}} \boldsymbol{\alpha}}{\mathrm{D}}$ & $P_{\exp }=\frac{u_{m} \alpha}{K_{L}}$ \\
\hline \multicolumn{7}{|l|}{ Berea gray } \\
\hline & 0.2 & 3.18 & 22.99 & 1.47 & 0.069 & 1.081 \\
\hline & 0.4 & 6.36 & 22.99 & 4.21 & 0.138 & 0.755 \\
\hline & 0.6 & 9.54 & 22.99 & 5.32 & 0.207 & 0.896 \\
\hline & 0.8 & 12.72 & 22.99 & 7.84 & 0.278 & 0.811 \\
\hline & 1.0 & 15.90 & 22.99 & 9.12 & 0.346 & 0.872 \\
\hline \multicolumn{7}{|l|}{ Bandera gray } \\
\hline & 0.2 & 3.36 & 22.99 & 5.36 & 0.074 & 0.313 \\
\hline & 0.4 & 6.72 & 22.99 & 7.80 & 0.146 & 0.431 \\
\hline & 0.6 & 10.08 & 22.99 & 10.10 & 0.219 & 0.499 \\
\hline & 0.8 & 13.44 & 22.99 & 10.35 & 0.292 & 0.649 \\
\hline & 1.0 & 16.80 & 22.99 & 13.13 & 0.365 & 0.640 \\
\hline
\end{tabular}

$\mathrm{K}_{\mathrm{L}}$ is the respective dispersion coefficient for each injection rate across the core samples.

Both samples recorded approximately the same average medium peclet number of 0.219 and 0.208 for Bandera and Berea gray respectively. The key factor responsible for this is the interstitial velocity since both $\alpha$ and $D$ are the same for the core plugs. However, considering the interstitial velocity equation, $u=\frac{Q}{\pi r^{2} \phi}$, it can be observed that porosity $(\phi)$ remain the only dependant variable. Meaning that the lower the porosity, the higher the injection flow velocity (Inversely proportion) since the same rate of injections $(\mathrm{Q})$ was employed for both plugs. Therefore, it is paramount that both would have approximately the same medium peclet number due to their nearness porosity values. This shows that the displacement mechanism lies in the transition zone between molecular diffusion and mechanical dispersion in both core plugs, driven by both concentration and velocity.

In contrast, using measured grain diameter of 94.66 and $57.15 \mu \mathrm{m}$ for Berea and Bandera gray, reported by Abba et al. (2018) as the characteristic length scale of mixing, medium peclet number was evaluated using Eq. 2.4, taking (u) as the average interstitial velocity of the runs as an input variable. The $P_{\text {em }}$ recorded were 0.03 and 0.04 which indicate that the flow mechanism is dominated by diffusion within the entire experimental tests for both core plugs since both values are $<0.1$ as earlier stated. With this, the selection of gas injection rates based on dispersivity value was quite misleading, and this could result in over or underestimation of transport parameters in porous media. The summary of the effect of injection rates on longitudinal dispersion coefficients of Berea and Bandera gray is presented in Table 10 .

\section{Table 10}

Summary of the effect of interstitial velocity on longitudinal dispersion coefficient

\begin{tabular}{ccccc}
\hline $\begin{array}{c}Q \\
(\mathrm{~m} / \mathrm{min})\end{array}$ & $\begin{array}{c}\text { Pressure } \\
(\mathrm{psig})\end{array}$ & $\begin{array}{c}\text { Temperature } \\
\left({ }^{0} \mathrm{C}\right)\end{array}$ & $\begin{array}{c}\text { Interstitial Velocity } \\
\left(10^{-5} \mathrm{~m} / \mathrm{s}\right)\end{array}$ & $\begin{array}{c}\text { Dispersion Coefficient } \\
\left(10^{-8} \mathrm{~m}^{2} / \mathrm{s}\right)\end{array}$ \\
\hline Berea gray & 1500 & 40 & & \\
0.2 & & & 3.18 & 1.47 \\
0.4 & & 6.36 & 4.21 \\
0.6 & & 9.54 & 5.32 \\
0.8 & & 12.72 & 7.84 \\
1.0 & & 15.90 & 9.12 \\
Bandera gray & & & \\
0.2 & & 3.36 & 5.36 \\
0.4 & & 6.72 & 7.80 \\
0.6 & & 10.08 & 10.10 \\
0.8 & & 13.44 & 10.35 \\
1.0 & & 16.80 & 13.13 \\
\hline
\end{tabular}


Generally, the longitudinal dispersion coefficient increases with an increase in flow velocity due to turbulence or eddy current development as evident in Table 10. Therefore, Bandera gray with the slightest permeability (32 mD) displayed a remarkably higher dispersion coefficient compared to Berea gray $(214 \mathrm{mD})$. Furthermore, since interstitial velocity is a function of porosity as earlier stated, the core plug with the highest porosity will record the lowest interstitial velocity with the least dispersion coefficients at lower injection rates as seen above. However, the dispersion coefficient rises remarkably at higher injection rates in both the core samples, with the highest value of $13.13 \times 10^{-8} \mathrm{~m}^{2} / \mathrm{s}$ recorded for Bandera gray compared to Berea gray with $9.12 \times 10^{-8} \mathrm{~m}^{2} / \mathrm{s}$ at maximum injection rate $(1.0 \mathrm{ml} / \mathrm{min})$. That is about $44 \%$ raise. In general, producing reservoirs are quantified based on pore volume (PV). For easier and error-free evaluation the original gas in place and residual methane recovery or residual methane volume recorded are quantified using a dimensionless parameter called Pore Volume (PV). This is defined as the ratio of the original gas in place or residual $\mathrm{CH}_{4}$ recovered to that of the grain volume recorded using Helium Porosimeter. The pore volume was determined to be 7.53 and $7.97 \mathrm{~cm}^{4}$ for Bandera and Berea gray core plugs respectively. The best $\mathrm{CH}_{4}$ recovery occurred at $0.4 \mathrm{ml} / \mathrm{min}$ injection. This yielded 819 and $652 \mathrm{~cm}^{3} \mathrm{CH}_{4}$ recoveries for Bandera and Berea grey. Thus, in turn, the PV values (103 and 87) were obtained as the ratio of 819 to 7.97 and 652 to 7.53 .

\section{Conclusion}

Identifying displacement phenomenon in fluid transport in porous media is quite important especially when investigating solute transport in sandstone rocks. The choice of the flow velocity in EGR thus becomes important since higher injection rates could lead to premature mixing of the fluids and lower injection rates generally provide longer resident times for the fluids in contact and indirectly increases the mixing of the gases again. The medium peclet numbers mostly indicate the best injection rates that translate to a smoother displacement with a lower dispersion coefficient during the EGR process, which gives an overview of the injection scenarios. In this study, Berea and Bandera gray sandstone core plugs were used as the standard porous medium to carry out a core flooding experiment to investigate the effect of injection velocity on $\mathrm{CH}_{4}$ recovery by nitrogen injection. The maximum $\mathrm{CH}_{4}$ recovery efficiency was recorded at breakthrough. The breakthrough is set at $10-15 \%$ of product contamination and the $\mathrm{CH}_{4}$ recovery efficiency was good at a lower injection rate for both core samples. This was due to less mixing observed as seen on their low longitudinal dispersion coefficient results. Consequently, the experimental runs at high injection rates $(0.6-1.0 \mathrm{ml} / \mathrm{min})$ present a different scenario with a poor recovery efficiency as a result of higher interstitial velocities as the $\mathrm{N}_{2}$ plumes transverses into the core sample during $\mathrm{CH}_{4}$ displacement. More so, high mean interstitial velocities $\left(u_{m}\right)$ grossly increases the molecular kinetic energy, by creating turbulence or eddy current which later influences the molecular agitation of gas species. Hence, it alleviates the interaction between the displacing and displaced gases. Maximum $\mathrm{CH}_{4}$ recovery was obtained at 0.4 $\mathrm{ml} / \mathrm{min}$ for both core samples and thus, Berea recorded $18 \%$ more in recovery than Bandera gray at the said injection. The recoveries were 103 and 87 pore volumes (PV) for Bandera and Berea gray core plugs respectively. Thus, with the results from the $\mathrm{CH}_{4}$ recovery efficiency and dispersion coefficient determination, it is apparent that the optimum injection was $0.4 \mathrm{ml} / \mathrm{min}$ for both core samples. The selection of gas injection rates based on dispersivity is quite misleading, and this could result in over or underestimation of transport parameters in porous media. The dispersion coefficient rises remarkably at higher injection rates for both the core plugs, with the highest value recorded on Bandera compared to Berea gray (about $44 \%$ higher) at the maximum injection rate. The effect of heterogeneity was more pronounced in Bandera than Berea gray. This could be due to the presence of high contents of clay minerals (Illite, chlorites, and kaolinites), which account for the large volumes of $\mathrm{CH}_{4}$ recovered compared to that of the Bandera core sample. The total clay contents were higher in Bandera than the Berea core sample with $75 \%$. Further work will entail an examination of the effect of heterogeneity on dispersion coefficient and $\mathrm{CH}_{4}$ recovery efficiency.

\section{Acknowledgements}

The authors wish to acknowledge the Petroleum Technology Development Fund (PTDF) for the studentship and Petroleum and Gas Research Group of the University of Salford, Manchester, UK, for their support.

\section{Nomenclature}

$\begin{array}{ll}y \mathrm{CO}_{2} & \mathrm{CO}_{2} \text { mole fraction } \\ y N_{2} & \mathrm{~N}_{2} \text { mole fraction } \\ D & \text { Diffusion coefficient, } \mathrm{m}^{2} / \mathrm{s} \\ Q & \text { Flowrate, mil/min } \\ t_{D} & \text { Dimensionless time } \\ x_{D} & \text { Dimensionless distance } \\ d & \text { Characteristic length scale, } \mathrm{m} \\ K_{L} & \text { Longitudinal dispersion, } \mathrm{m}^{2} / \mathrm{s} \\ L & \text { Core sample length, } \mathrm{mm} \\ L_{\mathrm{exp}} & \text { Experimental length, } \mathrm{m} \\ \mu & \text { Viscosity, cP } \\ P & \text { Pressure, psig }\end{array}$




$\begin{array}{ll}T & \text { Temperature, } \mathrm{K} \\ u & \text { Interstitial velocity, } \mathrm{m} / \mathrm{s} \\ \phi & \text { Core porosity, } \% \\ \alpha & \text { Dispersivity, } \mathrm{m} \\ T & \text { Tortuosity } \\ P_{\text {exp }} & \text { Experimental Peclet number } \\ P_{\text {em }} & \text { Medium Peclet number } \\ \mathrm{r} & \text { Radius of core sample, } \mathrm{m}\end{array}$

\section{Appendix}

Table 11

Berea gray effluent mole fraction of $\mathrm{N}_{2}$ produced recorded from the $\mathrm{GC}$ for the experimental runs

\begin{tabular}{|c|c|c|c|c|c|c|c|c|c|}
\hline \multicolumn{2}{|c|}{ Injection at $0.2 \mathrm{ml}$} & \multicolumn{2}{|c|}{ Injection at $0.4 \mathrm{ml}$} & \multicolumn{2}{|c|}{ Injection at $0.6 \mathrm{ml}$} & \multicolumn{2}{|c|}{ Injection at $0.8 \mathrm{ml}$} & \multicolumn{2}{|c|}{ Injection at $1.0 \mathrm{ml}$} \\
\hline $\begin{array}{l}\text { Time } \\
\text { (min) }\end{array}$ & $\begin{array}{c}\mathrm{N}_{2} \\
\left(\mathrm{yN}_{2}\right)\end{array}$ & $\begin{array}{l}\text { Time } \\
(\min )\end{array}$ & $\begin{array}{c}\mathrm{N}_{2} \\
\left(\mathrm{yN}_{2}\right)\end{array}$ & $\begin{array}{l}\text { Time } \\
(\min )\end{array}$ & $\begin{array}{c}\mathrm{N}_{2} \\
\left(\mathrm{yN}_{2}\right)\end{array}$ & $\begin{array}{l}\text { Time } \\
\text { (min) }\end{array}$ & $\begin{array}{c}\mathrm{N}_{2} \\
\left(\mathrm{yN}_{2}\right)\end{array}$ & $\begin{array}{l}\text { Time } \\
\text { (min) }\end{array}$ & $\begin{array}{c}\mathrm{N}_{2} \\
\left(\mathrm{yN}_{2}\right)\end{array}$ \\
\hline 0.16 & 0.001 & 0.15 & 0.001 & 0.15 & 0.001 & 0.15 & 0.001 & 0.16 & 0.001 \\
\hline 6.33 & 0.001 & 6.32 & 0.001 & 6.32 & 0.001 & 5.98 & 0.001 & 6.83 & 0.001 \\
\hline 11.99 & 0.001 & 12.15 & 0.001 & 12.15 & 0.001 & 11.32 & 0.001 & 12.49 & 0.001 \\
\hline 17.49 & 0.001 & 18.48 & 0.001 & 18.15 & 0.001 & 18.65 & 0.011 & 18.16 & 0.001 \\
\hline 23.32 & 0.001 & 24.15 & 0.001 & 24.48 & 0.031 & 24.15 & 0.018 & 21.82 & 0.001 \\
\hline 28.82 & 0.001 & 32.98 & 0.001 & 30.32 & 0.051 & 29.48 & 0.040 & 29.17 & 0.002 \\
\hline 34.49 & 0.001 & 38.65 & 0.001 & 35.98 & 0.083 & 34.82 & 0.081 & 34.49 & 0.020 \\
\hline 40.82 & 0.011 & 44.32 & 0.001 & 42.15 & 0.132 & 40.15 & 0.146 & 39.99 & 0.115 \\
\hline 46.66 & 0.015 & 50.32 & 0.001 & 47.82 & 0.200 & 46.98 & 0.232 & 45.32 & 0.343 \\
\hline 52.99 & 0.02 & 55.82 & 0.016 & 53.32 & 0.286 & 53.48 & 0.332 & 50.66 & 0.618 \\
\hline 58.66 & 0.026 & 61.98 & 0.020 & 58.82 & 0.391 & 58.98 & 0.436 & 55.99 & 0.826 \\
\hline 64.32 & 0.034 & 67.65 & 0.021 & 64.48 & 0.523 & 64.32 & 0.541 & 61.49 & 0.925 \\
\hline 70.32 & 0.043 & 73.32 & 0.122 & 69.98 & 0.653 & 69.98 & 0.651 & 66.83 & 0.958 \\
\hline 76.16 & 0.053 & 78.82 & 0.153 & 75.65 & 0.767 & 75.32 & 0.745 & 72.33 & 0.980 \\
\hline 81.99 & 0.065 & 84.48 & 0.186 & 81.65 & 0.855 & 81.15 & 0.804 & 77.83 & 0.986 \\
\hline 87.66 & 0.079 & 90.32 & 0.222 & 87.48 & 0.912 & 86.82 & 0.858 & 83.32 & 0.987 \\
\hline 93.33 & 0.144 & 95.98 & 0.262 & 93.15 & 0.943 & 92.32 & 0.894 & & \\
\hline 99.16 & 0.245 & 101.66 & 0.305 & 98.65 & 0.965 & 98.65 & 0.918 & & \\
\hline 104.82 & 0.353 & 108.32 & 0.349 & 104.32 & 0.974 & 103.99 & 0.934 & & \\
\hline 110.66 & 0.462 & 113.98 & 0.395 & 110.32 & 0.981 & 110.48 & 0.945 & & \\
\hline 116.5 & 0.559 & 119.65 & 0.442 & 116.65 & 0.983 & 115.82 & 0.958 & & \\
\hline 122.49 & 0.648 & 125.32 & 0.489 & & & 121.48 & 0.959 & & \\
\hline 127.99 & 0.763 & 130.98 & 0.556 & & & 126.98 & 0.962 & & \\
\hline 133.99 & 0.776 & 136.65 & 0.604 & & & 133.32 & 0.968 & & \\
\hline 139.99 & 0.873 & 142.32 & 0.650 & & & 139.15 & 0.973 & & \\
\hline 145.82 & 0.932 & 148.15 & 0.696 & & & 144.49 & 0.978 & & \\
\hline 151.49 & 0.954 & 153.65 & 0.742 & & & 149.82 & 0.979 & & \\
\hline 157.67 & 0.964 & 161.15 & 0.783 & & & 155.15 & 0.981 & & \\
\hline 163.32 & 0.969 & 167.15 & 0.820 & & & 160.65 & 0.985 & & \\
\hline
\end{tabular}




$\begin{array}{llllll}168.83 & 0.973 & 173.15 & 0.853 & 165.98 & 0.988 \\ 174.82 & 0.975 & 178.66 & 0.881 & & \\ 180.49 & 0.978 & 184.32 & 0.903 & \\ 186.82 & 0.98 & 190.15 & 0.921 & \\ 192.50 & 0.982 & 196.32 & 0.937 & \\ 199.00 & 0.984 & 201.82 & 0.950 & \\ 205.32 & 0.985 & 207.48 & 0.961 & \\ 210.99 & 0.985 & 212.99 & 0.970 & \\ 216.49 & 0.986 & 218.82 & 0.976 & \\ 222.16 & 0.986 & 230.66 & 0.979 & \\ 228.49 & 0.987 & 237.15 & 0.983 & \\ 236.82 & 0.988 & & & \\ 242.32 & 0.990 & & & \\ 248.16 & 0.994 & & \end{array}$

Table 12

Bandera gray effluent mole fraction of $\mathrm{N}_{2}$ produced recorded from the $\mathrm{GC}$ for the experimental runs

\begin{tabular}{|c|c|c|c|c|c|c|c|c|c|}
\hline \multicolumn{2}{|c|}{ Injection at $0.2 \mathrm{ml}$} & \multicolumn{2}{|c|}{ Injection at $0.4 \mathrm{ml}$} & \multicolumn{2}{|c|}{ Injection at $0.6 \mathrm{ml}$} & \multicolumn{2}{|c|}{ Injection at $0.8 \mathrm{ml}$} & \multicolumn{2}{|c|}{ Injection at $1.0 \mathrm{ml}$} \\
\hline $\begin{array}{l}\text { Time } \\
\text { (min) }\end{array}$ & $\begin{array}{c}\mathrm{N}_{2} \\
\left(\mathrm{yN}_{2}\right)\end{array}$ & $\begin{array}{l}\text { Time } \\
\text { (min) }\end{array}$ & $\begin{array}{c}\mathrm{N}_{2} \\
\left(\mathrm{yN}_{2}\right)\end{array}$ & $\begin{array}{l}\text { Time } \\
\text { (min) }\end{array}$ & $\begin{array}{c}\mathrm{N}_{2} \\
\left(\mathrm{yN}_{2}\right)\end{array}$ & $\begin{array}{l}\text { Time } \\
(\mathrm{min})\end{array}$ & $\begin{array}{c}\mathrm{N}_{2} \\
\left(\mathrm{yN}_{2}\right)\end{array}$ & $\begin{array}{l}\text { Time } \\
\text { (min) }\end{array}$ & $\begin{array}{c}\mathrm{N}_{2} \\
\left(\mathrm{yN}_{2}\right)\end{array}$ \\
\hline 0.16 & 0.001 & 0.16 & 0.001 & 0.15 & 0.001 & 0.17 & 0.001 & 0.15 & 0.001 \\
\hline 3.99 & 0.001 & 5.49 & 0.001 & 3.48 & 0.001 & 5.83 & 0.001 & 2.48 & 0.001 \\
\hline 9.32 & 0.001 & 11.99 & 0.001 & 8.82 & 0.001 & 11.33 & 0.001 & 7.98 & 0.001 \\
\hline 14.66 & 0.001 & 18.16 & 0.001 & 14.16 & 0.001 & 15.49 & 0.001 & 13.82 & 0.001 \\
\hline 19.99 & 0.001 & 23.49 & 0.001 & 19.48 & 0.001 & 21.29 & 0.013 & 19.32 & 0.001 \\
\hline 25.65 & 0.001 & 28.82 & 0.001 & 24.82 & 0.001 & 26.82 & 0.153 & 24.65 & 0.015 \\
\hline 32.48 & 0.001 & 34.16 & 0.001 & 30.48 & 0.001 & 31.99 & 0.383 & 29.98 & 0.029 \\
\hline 38.48 & 0.001 & 39.66 & 0.001 & 35.65 & 0.054 & 37.99 & 0.609 & 35.32 & 0.100 \\
\hline 43.82 & 0.001 & 44.99 & 0.001 & 41.16 & 0.169 & 43.5 & 0.79 & 40.82 & 0.227 \\
\hline 49.16 & 0.001 & 50.32 & 0.001 & 46.48 & 0.322 & 48.82 & 0.884 & 46.32 & 0.378 \\
\hline 54.48 & 0.001 & 55.82 & 0.001 & 51.82 & 0.491 & 54.15 & 0.934 & 51.66 & 0.524 \\
\hline 59.82 & 0.001 & 61.16 & 0.001 & 57.15 & 0.649 & 59.49 & 0.96 & 57.16 & 0.656 \\
\hline 65.15 & 0.001 & 66.49 & 0.001 & 62.99 & 0.777 & 65 & 0.971 & 63.98 & 0.753 \\
\hline 70.82 & 0.001 & 71.82 & 0.001 & 68.32 & 0.857 & 70.32 & 0.977 & 69.32 & 0.839 \\
\hline 76.32 & 0.032 & 77.16 & 0.018 & 73.82 & 0.907 & 75.66 & 0.98 & 74.83 & 0.884 \\
\hline 82.15 & 0.708 & 82.49 & 0.057 & 79.15 & 0.937 & 81.15 & 0.982 & 80.15 & 0.914 \\
\hline 87.65 & 0.957 & 87.82 & 0.512 & 84.65 & 0.957 & 86.65 & 0.984 & 85.83 & 0.935 \\
\hline 95.15 & 0.98 & 93.16 & 0.845 & 90.32 & 0.97 & 92.5 & 0.984 & 91.15 & 0.95 \\
\hline 100.98 & 0.982 & 98.66 & 0.937 & 95.82 & 0.976 & 98 & 0.985 & 96.48 & 0.959 \\
\hline 106.32 & 0.983 & 103.99 & 0.963 & 101.15 & 0.981 & 104 & 0.985 & 101.82 & 0.965 \\
\hline 112.98 & 0.983 & 109.32 & 0.969 & 106.65 & 0.982 & 109.3 & 0.986 & 107.32 & 0.97 \\
\hline \multirow[t]{2}{*}{118.82} & 0.984 & 114.66 & 0.97 & 111.99 & 0.984 & & & 112.65 & 0.973 \\
\hline & & & & & & & & 117.98 & 0.976 \\
\hline
\end{tabular}


Table 13

Berea gray $\mathrm{CH}_{4}$ production in pore volumes for all the experimental runs

\begin{tabular}{|c|c|c|c|c|c|c|c|c|c|}
\hline \multicolumn{2}{|c|}{$0.2 \mathrm{ml}$ Injection } & \multicolumn{2}{|c|}{$0.4 \mathrm{ml}$ Injection } & \multicolumn{2}{|c|}{$0.6 \mathrm{ml}$ Injection } & \multicolumn{2}{|c|}{$0.8 \mathrm{ml}$ Injection } & \multicolumn{2}{|c|}{ 1.0ml Injection } \\
\hline $\begin{array}{c}\text { Time } \\
(\min ) \\
0.16\end{array}$ & $\begin{array}{c}\mathrm{CH}_{4} \text { Prod } \\
\text { (PV) } \\
4.17\end{array}$ & $\begin{array}{c}\text { Time } \\
(\min ) \\
0.15\end{array}$ & $\begin{array}{c}\mathrm{CH}_{4} \text { Prod } \\
\text { (PV) } \\
4.48\end{array}$ & $\begin{array}{c}\text { Time } \\
(\min ) \\
0.15\end{array}$ & $\begin{array}{c}\mathrm{CH}_{4} \text { Prod } \\
(\mathrm{PV}) \\
7.81\end{array}$ & $\begin{array}{c}\text { Time } \\
(\mathrm{min}) \\
0.15\end{array}$ & $\begin{array}{c}\mathrm{CH}_{4} \text { Prod } \\
\text { (PV) } \\
4.65\end{array}$ & $\begin{array}{c}\text { Time } \\
(\mathrm{min}) \\
0.16\end{array}$ & $\begin{array}{c}\mathrm{CH}_{4} \mathrm{Prod} \\
(\mathrm{PV}) \\
6.61\end{array}$ \\
\hline 6.33 & 5.58 & 6.32 & 6.14 & 6.32 & 12.10 & 5.98 & 9.36 & 6.83 & 12.31 \\
\hline 11.99 & 9.82 & 12.15 & 10.72 & 12.15 & 18.08 & 11.32 & 14.13 & 12.49 & 19.20 \\
\hline 17.49 & 14.06 & 18.48 & 15.40 & 18.15 & 22.31 & 18.65 & 18.80 & 18.16 & 26.37 \\
\hline 23.32 & 18.34 & 24.15 & 20.11 & 24.48 & 26.02 & 24.15 & 23.24 & 21.82 & 33.71 \\
\hline 28.82 & 22.65 & 32.98 & 22.00 & 30.32 & 29.85 & 29.48 & 27.54 & 29.17 & 40.51 \\
\hline 34.49 & 27.00 & 38.65 & 26.86 & 35.98 & 36.89 & 34.82 & 31.06 & 34.49 & 45.99 \\
\hline 40.82 & 31.06 & 44.32 & 31.79 & 42.15 & 39.28 & 40.15 & 33.29 & 39.99 & 47.97 \\
\hline 46.66 & 35.25 & 50.32 & 36.75 & 47.82 & 40.49 & 46.98 & 34.00 & 45.32 & 39.49 \\
\hline 52.99 & 39.43 & 55.82 & 41.15 & 53.32 & 40.15 & 53.48 & 33.18 & 50.66 & 24.94 \\
\hline 58.66 & 40.80 & 61.98 & 45.95 & 58.82 & 37.72 & 58.98 & 31.11 & 55.99 & 11.63 \\
\hline 64.32 & 44.65 & 67.65 & 47.01 & 64.48 & 34.39 & 64.32 & 27.87 & 61.49 & 5.45 \\
\hline 70.32 & 48.56 & 73.32 & 50.19 & 69.98 & 28.65 & 69.98 & 23.17 & 66.83 & 3.15 \\
\hline 76.16 & 52.32 & 78.82 & 52.84 & 75.65 & 21.76 & 75.32 & 18.40 & 72.33 & 1.55 \\
\hline 81.99 & 56.00 & 84.48 & 55.05 & 81.65 & 15.17 & 81.15 & 15.30 & 77.83 & 1.12 \\
\hline 87.66 & 59.41 & 90.32 & 56.73 & 87.48 & 10.02 & 86.82 & 11.94 & 83.32 & 1.08 \\
\hline 93.33 & 56.82 & 95.98 & 57.75 & 93.15 & 7.00 & 92.32 & 9.56 & & \\
\hline 99.16 & 53.64 & 101.66 & 58.22 & 98.65 & 4.66 & 98.65 & 7.91 & & \\
\hline 104.82 & 48.54 & 108.32 & 58.09 & 104.32 & 3.73 & 103.99 & 6.80 & & \\
\hline 110.66 & 42.91 & 113.98 & 57.31 & 110.32 & 2.91 & 110.48 & 6.02 & & \\
\hline 116.50 & 37.09 & 119.65 & 55.96 & 116.65 & 2.79 & 115.82 & 4.87 & & \\
\hline 122.49 & 27.98 & 125.32 & 54.12 & & & 121.48 & 5.03 & & \\
\hline 127.99 & 22.09 & 130.98 & 49.55 & & & 126.98 & 4.89 & & \\
\hline 133.99 & 21.93 & 136.65 & 46.47 & & & 133.32 & 4.29 & & \\
\hline 139.99 & 12.82 & 142.32 & 43.14 & & & 139.15 & 3.76 & & \\
\hline 145.82 & 7.20 & 148.15 & 39.26 & & & 144.49 & 3.19 & & \\
\hline 151.49 & 5.09 & 153.65 & 34.86 & & & 149.82 & 3.17 & & \\
\hline 157.67 & 4.08 & 161.15 & 30.63 & & & 155.15 & 2.97 & & \\
\hline 163.32 & 3.67 & 167.15 & 25.53 & & & 160.65 & 2.42 & & \\
\hline 168.83 & 3.25 & 173.15 & 21.23 & & & 165.98 & 2.00 & & \\
\hline 174.82 & 3.06 & 178.66 & 17.49 & & & & & & \\
\hline 180.49 & 2.74 & 184.32 & 14.53 & & & & & & \\
\hline 186.82 & 2.60 & 190.15 & 12.04 & & & & & & \\
\hline 192.50 & 2.42 & 196.32 & 9.77 & & & & & & \\
\hline 199.00 & 2.19 & 201.82 & 7.90 & & & & & & \\
\hline 205.32 & 2.09 & 207.48 & 6.28 & & & & & & \\
\hline 210.99 & 2.12 & 212.99 & 4.93 & & & & & & \\
\hline \multirow[t]{3}{*}{216.49} & 2.01 & 218.82 & 4.01 & & & & & & \\
\hline & & 230.66 & 3.57 & & & & & & \\
\hline & & 237.15 & 2.95 & & & & & & \\
\hline
\end{tabular}


Table 14

Bandera gray $\mathrm{CH}_{4}$ production in pore volumes for all the experimental runs

\begin{tabular}{|c|c|c|c|c|c|c|c|c|c|}
\hline \multicolumn{2}{|c|}{$0.2 \mathrm{ml}$ Injection } & \multicolumn{2}{|c|}{$0.4 \mathrm{ml}$ Injection } & \multicolumn{2}{|c|}{$0.6 \mathrm{ml}$ Injection } & \multicolumn{2}{|c|}{$0.8 \mathrm{ml}$ Injection } & \multicolumn{2}{|c|}{ 1.0ml Injection } \\
\hline $\begin{array}{c}\text { Time } \\
(\min ) \\
0.16\end{array}$ & $\begin{array}{c}\mathrm{CH}_{4} \text { Prod } \\
\text { (PV) } \\
0.02\end{array}$ & $\begin{array}{l}\text { Time } \\
(\min ) \\
0.16\end{array}$ & $\begin{array}{c}\mathrm{CH}_{4} \text { Prod } \\
\text { (PV) } \\
0.02\end{array}$ & $\begin{array}{c}\text { Time } \\
(\min ) \\
0.15\end{array}$ & $\begin{array}{c}\mathrm{CH}_{4} \text { Prod } \\
\text { (PV) } \\
0.02\end{array}$ & $\begin{array}{c}\text { Time } \\
(\min ) \\
0.17\end{array}$ & $\begin{array}{c}\mathrm{CH}_{4} \text { Prod } \\
\text { (PV) } \\
0.02\end{array}$ & $\begin{array}{c}\text { Time } \\
(\mathrm{min}) \\
0.15\end{array}$ & $\begin{array}{c}\mathrm{CH}_{4} \mathrm{Prod} \\
(\mathrm{PV}) \\
0.02\end{array}$ \\
\hline 3.99 & 0.53 & 5.49 & 0.73 & 3.48 & 0.46 & 5.83 & 0.77 & 2.48 & 0.33 \\
\hline 9.32 & 1.24 & 11.99 & 1.59 & 8.82 & 1.17 & 11.33 & 1.51 & 7.98 & 1.06 \\
\hline 14.66 & 1.95 & 18.16 & 2.41 & 14.16 & 1.88 & 15.49 & 2.06 & 13.82 & 1.84 \\
\hline 19.99 & 2.66 & 23.49 & 3.12 & 19.48 & 2.59 & 21.29 & 2.83 & 19.32 & 2.57 \\
\hline 25.65 & 3.41 & 28.82 & 3.83 & 24.82 & 3.30 & 26.82 & 3.56 & 24.65 & 3.27 \\
\hline 32.48 & 4.31 & 34.16 & 4.54 & 30.48 & 4.05 & 31.99 & 4.25 & 29.98 & 3.98 \\
\hline 38.48 & 5.11 & 39.66 & 5.27 & 35.65 & 4.73 & 37.99 & 5.05 & 35.32 & 4.69 \\
\hline 43.82 & 5.82 & 44.99 & 5.98 & 41.16 & 5.47 & 43.5 & 5.78 & 40.82 & 5.42 \\
\hline 49.16 & 6.53 & 50.32 & 6.68 & 46.48 & 6.17 & 48.82 & 6.48 & 46.32 & 6.15 \\
\hline 54.48 & 7.24 & 55.82 & 7.41 & 51.82 & 6.88 & 54.15 & 7.19 & 51.66 & 6.86 \\
\hline 59.82 & 7.94 & 61.16 & 8.12 & 57.15 & 7.59 & 59.49 & 7.90 & 57.16 & 7.59 \\
\hline 65.15 & 8.65 & 66.49 & 8.83 & 62.99 & 8.37 & 65.00 & 8.63 & 63.98 & 8.50 \\
\hline 70.82 & 9.41 & 71.82 & 9.54 & 68.32 & 9.07 & 70.32 & 9.34 & 69.32 & 9.21 \\
\hline 76.32 & 10.14 & 77.16 & 10.25 & 73.82 & 9.80 & 75.66 & 10.05 & 74.83 & 9.94 \\
\hline 82.15 & 10.91 & 82.49 & 10.95 & 79.15 & 10.51 & 81.15 & 10.78 & 80.15 & 10.64 \\
\hline 87.65 & 11.64 & 87.82 & 11.66 & 84.65 & 11.24 & 86.65 & 11.51 & 85.83 & 11.40 \\
\hline 95.15 & 12.64 & 93.16 & 12.37 & 90.32 & 11.99 & 92.50 & 12.28 & 91.15 & 12.10 \\
\hline 100.98 & 13.41 & 98.66 & 13.10 & 95.82 & 12.73 & 98.00 & 13.01 & 96.48 & 12.81 \\
\hline 106.32 & 14.12 & 103.99 & 13.81 & 101.15 & 13.43 & 104.00 & 13.81 & 101.82 & 13.52 \\
\hline 112.98 & 15.00 & 109.32 & 14.52 & 106.65 & 14.16 & 109.30 & 14.52 & 107.32 & 14.25 \\
\hline \multirow[t]{2}{*}{118.82} & 15.78 & 114.66 & 15.23 & 111.99 & 14.87 & & & 112.65 & 14.96 \\
\hline & & & & & & & & 117.98 & 15.67 \\
\hline
\end{tabular}

Table 15

Dispersion coefficients of $\mathrm{N}_{2}-\mathrm{CH}_{4}$ as functions of concentration profiles

\begin{tabular}{|c|c|c|c|c|c|c|}
\hline $\begin{array}{c}\text { Core } \\
\text { Samples }\end{array}$ & $\begin{array}{c}\mathbf{Q} \\
(\mathrm{ml} / \mathrm{min})\end{array}$ & $\begin{array}{c}\mathrm{u} \\
\left(10^{-5} \mathrm{~m} / \mathrm{s}\right)\end{array}$ & $\begin{array}{c}\mathrm{K} \mathrm{L} \\
\left(10^{-8} \mathrm{~m}^{2} / \mathrm{s}\right)\end{array}$ & $\begin{array}{c}D \\
\left(10^{-8} \mathrm{~m}^{2} / \mathrm{s}\right)\end{array}$ & $\begin{array}{l}\mathbf{u} / \mathbf{D} \\
\left(\mathrm{m}^{-1}\right)\end{array}$ & $\mathrm{K}_{\mathrm{L}} / \mathrm{D}$ \\
\hline \multicolumn{7}{|l|}{ Berea gray } \\
\hline & 0.2 & 3.18 & 1.47 & 22.99 & 138.28 & 0.100 \\
\hline & 0.4 & 6.36 & 4.21 & 22.99 & 276.56 & 0.183 \\
\hline & 0.6 & 9.54 & 5.32 & 22.99 & 414.83 & 0.231 \\
\hline & 0.8 & 12.72 & 7.84 & 22.99 & 553.28 & 0.341 \\
\hline & 1.0 & 15.90 & 9.12 & 22.99 & 691.61 & 0.397 \\
\hline \multicolumn{7}{|l|}{ Bandera gray } \\
\hline & 0.2 & 3.38 & 5.36 & 22.99 & 146.15 & 0.233 \\
\hline & 0.4 & 6.72 & 7.80 & 22.99 & 292.30 & 0.339 \\
\hline & 0.6 & 10.08 & 10.10 & 22.99 & 438.45 & 0.439 \\
\hline & 0.8 & 13.44 & 10.35 & 22.99 & 584.60 & 0.450 \\
\hline & 1.0 & 16.80 & 13.13 & 22.99 & 730.75 & 0.571 \\
\hline
\end{tabular}




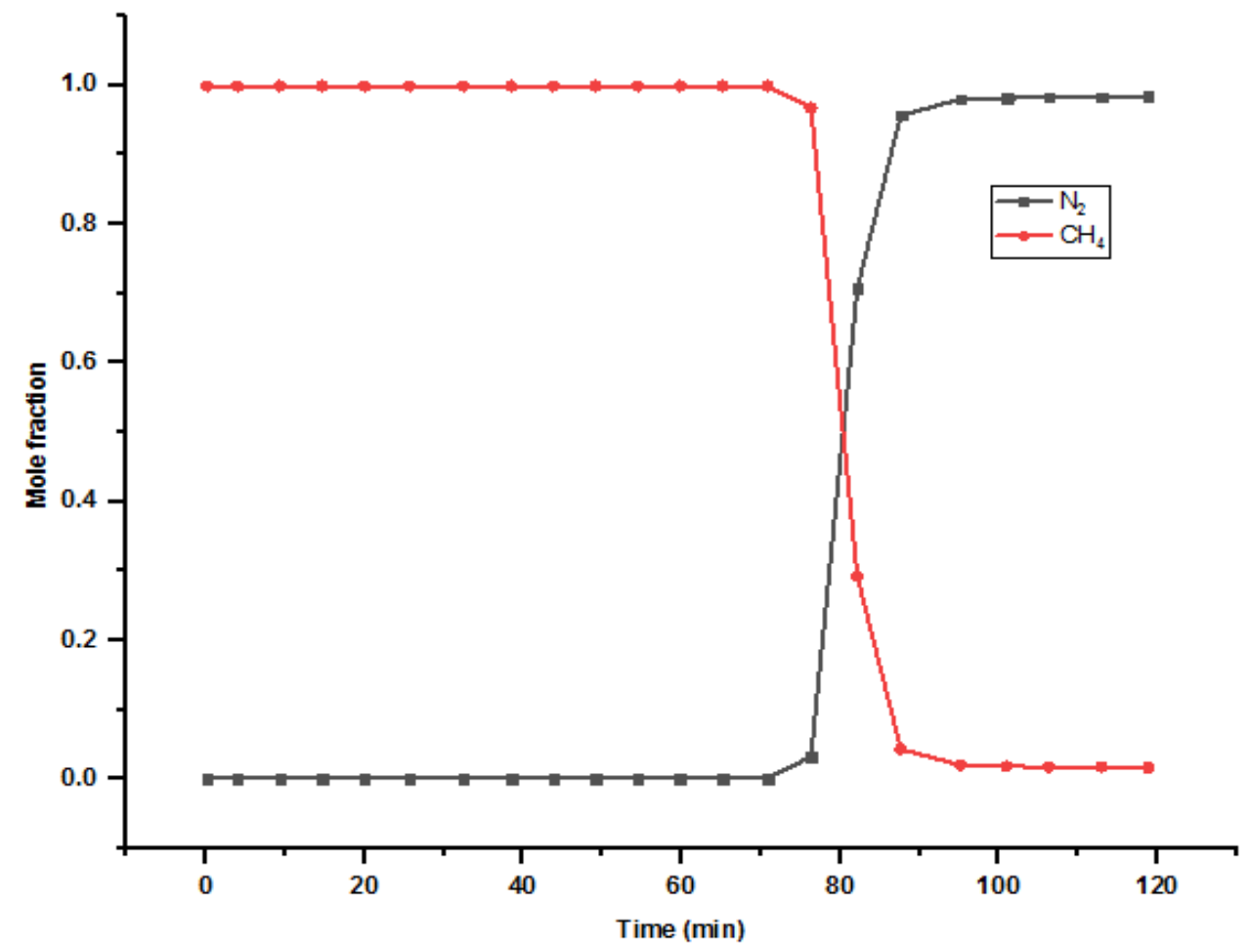

Fig. 11. Effluent $\mathrm{N}_{2}$ and $\mathrm{CH}_{4}$ composition recorded from the $\mathrm{GC}$ as a function of displacement time for Bandera gray

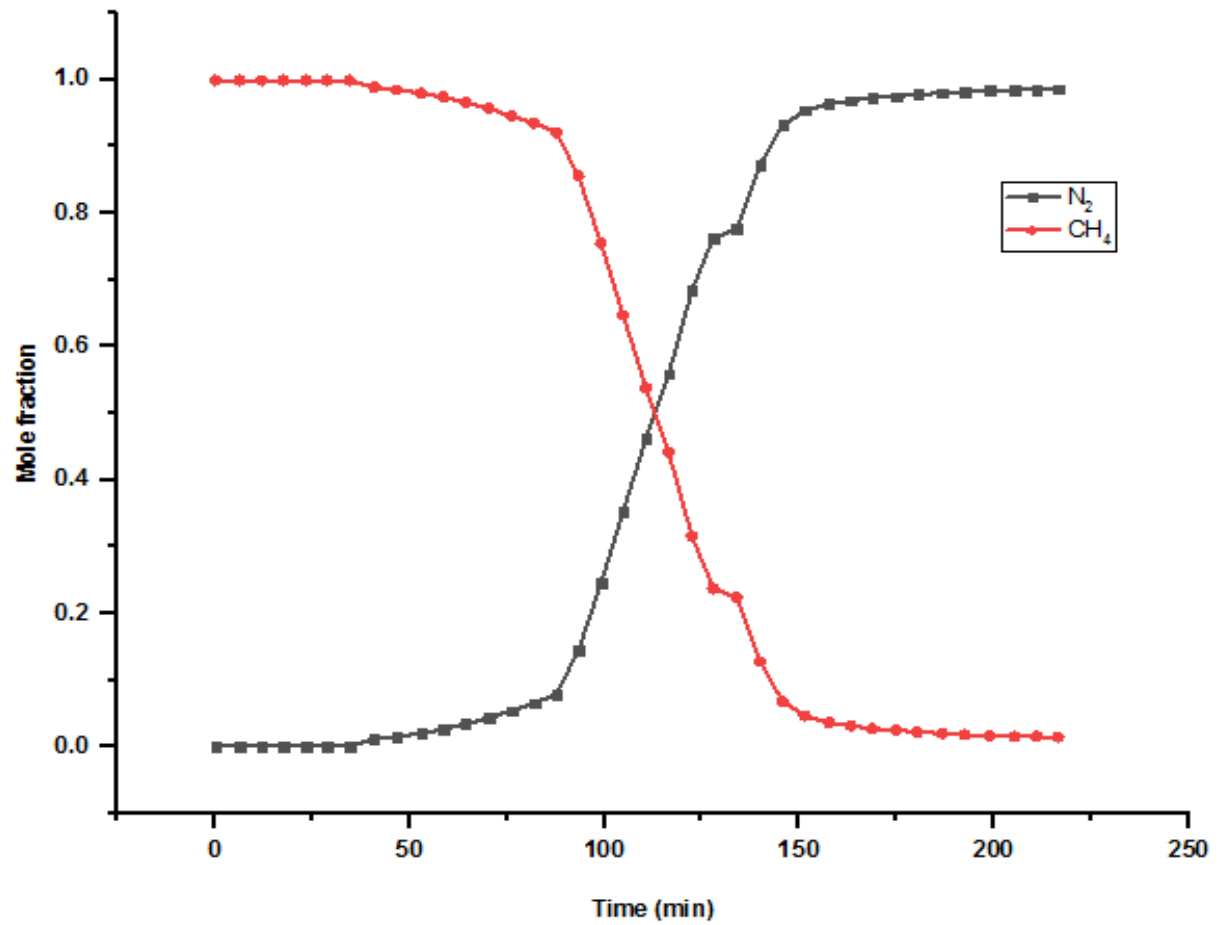

Fig. 12. Effluent $\mathrm{N}_{2}$ and $\mathrm{CH}_{4}$ composition recorded from the $\mathrm{GC}$ as a function of displacement time for Berea gray 


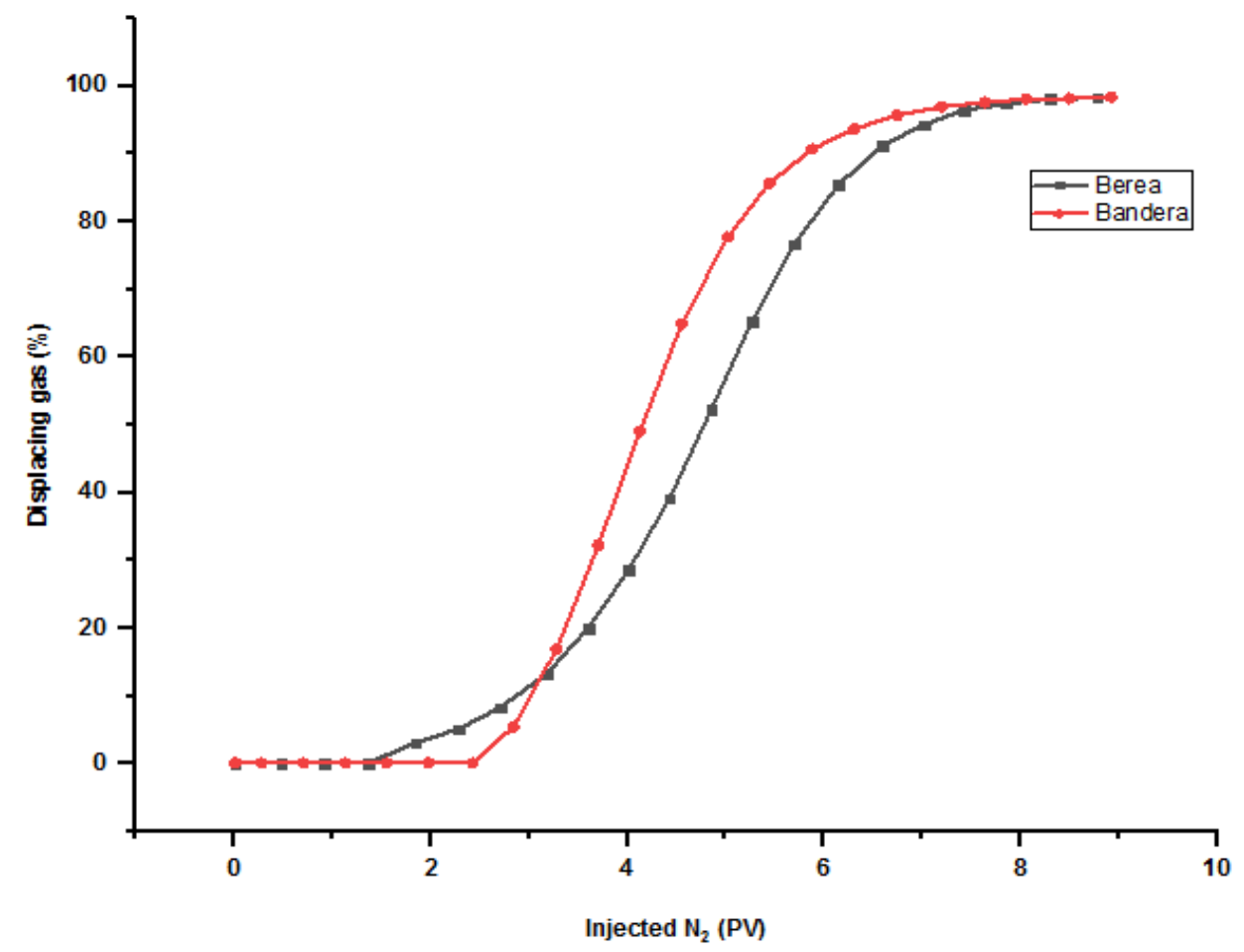

Fig. 13. Effluent concentration as a function of pore volumes injected observed during a core flooding experiment with $\mathrm{N}_{2}$ and $\mathrm{CH}_{4}$ as displacing and displaced gases at the rate of $0.6 \mathrm{ml} / \mathrm{min}$

\section{References}

Abba, M.K., Abbas, A.J., Athari, A., Mukhtar, A., \& Nasr, G.G. (2018). Experimental Investigation on the Impact of Connate Water Salinity on Dispersion Coefficient in Consolidated Rocks Cores during EGR by $\mathrm{CO}_{2}$ Injection. Journal of Natural Gas Science and Engineering, 60, 190-201. http://doi.org/10.1016/i.jngse.2018.10.007.

Abba, M.K., Abbas, A.J. \& Nasr, G.G. (2017). Enhanced Gas Recovery by $\mathrm{CO}_{2}$ Injection and Sequestration: Effect of Connate Water Salinity on Displacement Efficiency. SPE Abu Dhabi International Petroleum Exhibition \& Conference. http://www.onepetro.org/doi/10.2118/188930MS.

Al-abri, A., Sidiq H. \& Amin R. (2009). Enhanced Natural Gas and Condensate Recovery by Injection of Pure $\mathrm{SCCO}_{2}$, Pure $\mathrm{CH}_{4}$ and Their Mixtures: Experimental Investigation. SPE Annual Technical Conference and Exhibition, New Orleans, Lousiana, USA, 4-7 October, 1-13.

Anonymous, 2020. NiGen Annual Report, 2020: https://nigen.com/nitrogen-injection-enhanced-oilrecovery-techniques-eor/

Coats, K.H., Whitson, C.H., Thomas, K. (2009). Modelling conformance as dispersion. SPE Reservoir Eval. Eng. 12, 33-47. https://doi.org/10.2118/90390-PA

Coats, K. H., \& Whitson, C. H. (2004). SPE 90390 Modelling Conformance as Dispersion.

Fuller, E. N., Schettler, P. D., and Giddings, J. C. (1966). New method for prediction of binary gas- 'phase diffusion coefficients, Ind. Eng. Chem., 58, 18-27.

Honari, A., Bijeljic, B., Johns, M. L., \& May, E. F. (2015). Enhanced gas recovery with $\left\{\mathrm{CO}_{2}\right\}$ sequestration: The effect of medium heterogeneity on the dispersion of supercritical $\mathrm{CO}_{2}-\mathrm{CH}_{4}$. International Journal of Greenhouse Gas Control, 39(0), 39-50. http://doi.org/http://dx.doi.org/10.1016/j.ijggc.2015.04.014

Honari, A., Hughes, T. J., Fridjonsson, E. O., Johns, M. L., \& May, E. F. (2013). Dispersion of supercritical $\mathrm{CO}_{2}$ and $\mathrm{CH}_{4}$ in consolidated porous media for enhanced gas recovery simulations. International Journal of Greenhouse Gas Control, 19, 234-242. http://doi.org/10.1016/j.ijggc.2013.08.016

Honari, A., Zecca, M., Vogt, S. J., Iglauer, S., Bijeljic, B., Johns, M. L., \& May, E. F. (2016). The impact of residual water on $\mathrm{CH}_{4}-\mathrm{CO}_{2}$ dispersion in consolidated rock cores. International Journal of Greenhouse Gas Control, 50, 100-111. http://doi.org/10.1016/j.jjggc.2016.04.004

Hughes, T. J., Honari, A., Graham, B. F., Chauhan, A. S., Johns, M. L., \& May, E. F. (2012). $\mathrm{CO}_{2}$ sequestration for enhanced gas recovery: New measurements of supercritical $\mathrm{CO}_{2}-\mathrm{CH}_{4}$ dispersion in porous media and a review of recent research. International Journal of Greenhouse Gas Control, 9, 457-468. http://doi.org/10.1016/j.ijggc.2012.05.011 
Huysmans, M., \& Dassargues, A. (2005). Review of the use of Peclet numbers to determine the relative importance of advection and diffusion in low permeability environments. Hydrogeology Journal, 13(5-6), 895-904. http://doi.org/10.1007/s10040-004-0387-4

Janssen, M. T. G., Azimi, F., Zitha, P. L. J. (2018). Immiscible Nitrogen Flooding in Bentheimer Sandstones: Comparing Gas Injection Schemes for Enhanced Oil Recovery. Society of Petroleum Engineers. Available at: doi:10.2118/190285-MS

Khan, C., Amin R. \& Madden G. (2013). Carbon dioxide injection for enhanced gas recovery and storage (reservoir simulation). Egyptian Journal of Petroleum, 22(2), 225-240. http://www.sciencedirect.com/science/ article/pii/S1110062113000500.

Liu, S., Zhang, Y., Xing, W., Jian, W., Liu, Z., Li, T., \& Song, Y. (2015). Laboratory experiment of $\mathrm{CO}_{2^{-}}$ $\mathrm{CH}_{4}$ displacement and dispersion in sandpacks in enhanced gas recovery. Journal of Natural Gas Science and Engineering, 26, 1585-1594. http://doi.org/10.1016/j.jngse.2015.04.021

Mamora, D.D., Seo, J.G., 2002. Enhanced recovery by carbon dioxide sequestration in depleted gas reservoirs. SPE Annu. Tech. Conf. Exhib. 1-9.

Newberg, M.., \& Foh, S., 1988. Measurement of Longitudinal Dispersion Coefficients for Gas Flowing Through Porous Media. SPE, 5-9.

Oldenburg, C.M. \& Benson S.M., 2002. $\mathrm{CO}_{2}$ Injection for Enhanced Gas Production and Carbon Sequestration. SPE International Petroleum Conference and Exhibition in Mexico. http://www.onepetro.org/ doi/10.2118/74367-MS.

Perkins, T.., \& Johnston, O. (1963). A Review of Diffusion and Dispersion in Porous Media. Society of Petroleum Engineers Journal, 3(01), 70-84. 10.2118/480-PA

Patel, M. J., May, E. F., \& Johns, M. L. (2016). High-fidelity reservoir simulations of enhanced gas recovery with supercritical $\mathrm{CO}_{2}$. Energy, IN PRESS, 548-559. http://doi.org/10.1016/j.energy.2016.04.120

Pooladi-Darvish, M., Hong, H., Theys, S., Stocker, R., Bachu, S., \& Dashtgard, S. (2008). $\mathrm{CO}_{2}$ injection for enhanced gas recovery and geological storage of $\mathrm{CO}_{2}$ in the Long Coulee Glauconite $\mathrm{F}$ Pool, Alberta. Proceedings - SPE Annual Technical Conference and Exhibition, 4, 2271-2281. http://doi.org/10.2118/115789-MS

Shtepani, E. (2006). $\mathrm{CO}_{2}$ sequestration in depleted gas/condensate reservoirs.

Sidiq, H., Amin, R., der Steen, E. Van, \& Kennaird, T. (2011a). Super critical $\mathrm{CO}_{2}$-methane relative permeability investigation. Journal of Petroleum Science and Engineering, 78(3-4),654-663. http://doi.org/10.1016/i.petrol.2011.08.018

Sim, S. S. K., Brunelle, P., Canada, Q., Systems, F., Turta, A. T., \& Singhal, A. K. (2008). SPE 113468 Enhanced Gas Recovery and $\mathrm{CO}_{2}$ Sequestration by Injection of Exhaust Gases from Combustion of Bitumen. Journal of Changes, (1), 1-10.

Sim, S. S. K., Turta, A. T., Singhal, A. K., \& Hawkins, B. F. (2009). Enhanced gas recovery: Factors affecting gasgas displacement efficiency. Journal of Canadian Petroleum Technology, 48(8), 49-55. http://doi.org/10.2118/09-08-49

Sim, S., Turta, A. T., Singhal, A., \& Hawkins, B. F. (2009). Enhanced Gas Recovery: Effect of Reservoir Heterogeneity on Gas-Gas Displacement. Candian International Petroleum Conference, (June), 1-14. http://doi.org/10.2118/2009-023

Turta, A. T., Sim, S. S. K., Singhal, A. K., \& Hawkins, B. F. (2007). Basic Investigations on Enhanced Gas Recovery by Gas-Gas Displacement.

Turta, A.T., S.S.K. Sim, A.K. Singhal, B.F. Hawkins (2009). Enhanced Gas Recovery: Factors Affecting Gas-Gas Displacement Efficiency. Journal of Canadian Petroleum Technology, 48(08), 1-12.

Takahashi, S., Iwasaki, H., 1970. The diffusion of gases at high pressures. III. The diffusion of $\mathrm{CO}_{2}$, in the $\mathrm{CO}_{2}-\mathrm{CH}_{4}$ system. Bulletin of the Chemical Research Institute of Non-Aqueous Solutions, Tohoku University 20, 27-36.

Xidong Du, Min Gu, Zhenjian Liu, Yuan Zhao, Fulong Sun, and Tengfei Wu, 2019. Enhanced Shale Gas Recovery by the Injections of $\mathrm{CO}_{2}, \mathrm{~N}_{2}$, and $\mathrm{CO}_{2} / \mathrm{N}_{2}$ Mixture Gases. Journal of energy and fuels. DOI: 10.1021/acs.energyfuels.9b00822

Yu, D., Jackson, K., \& Harmon, T. C. (1999). Dispersion and diffusion in porous media under supercritical conditions. Chemical Engineering Science, 54(3), 357-367. http://doi.org/10.1016/S00092509(98)00271-1

Zhang, Y., Liu, S., Song, Y., Zhao, J., Tang, L., Xing, W., Jian, W., Liu, Z., Zhan, Y. (2014). Experimental investigation of $\mathrm{CO}_{2}-\mathrm{CH}_{4}$ displacement and dispersion in sand pack for enhanced gas recovery. Energy Procedia, 61, 393-397. http://dx.doi.org/10.1016/i.egypro.2014.11.1133. 